\title{
¿Un espacio rioplatense ampliado? Análisis de una economía agraria en el sur de Brasil (Triunfo y Santo Amaro, 1784-1849)
}

por

\section{Helen Osório ${ }^{1}$}

Programa de Pós-Graduação em História Universidade Federal do Rio Grande do Sul, Brasil

\section{Juan Luis Martirén ${ }^{2}$}

Instituto de Historia Argentina y Americana "Dr. Emilio Ravignani" - UBA / Conicet, Argentina

El artículo analiza la evolución de una economía agraria de frontera en el extremo meridional de Brasil entre 1784 y 1849. Los casos elegidos son las freguesias (parroquias) de Triunfo y Santo Amaro, localizadas en lo que actualmente es el estado do Rio Grande do Sul. Se trata de dos casos de peso geográfico y económico, ya que no sólo su establecimiento tuvo una importancia estratégica en el poblamiento de la frontera meridional portuguesa en América, sino que a la vez experimentaron un marcado crecimiento de la agricultura en el periodo colonial y de la industria de saladeros desde la década de 1820. A partir de la utilización de registros censales e inventarios post-mortem se busca mensurar los cambios y continuidades en la ganadería, la agricultura y en las estrategias de producción. Los resultados encontrados van muy en línea con los ya conocidos para Rio Grande do Sul en el período, y tienen ciertas coincidencias con los conocidos para el Río de la Plata.

Palabras Clave: agricultura; ganadería; Capitanía de Rio Grande; Río de la Plata.

Cómo Citar Este Artículo / Citation: Osório, Helen y Martirén, Juan Luis, “¿Un espacio rioplatense ampliado? Análisis de una economía agraria en el sur de Brasil (Triunfo y Santo Amaro, 1784-1849)", Revista de Indias, LXXXI/282 (Madrid, 2021): 407-440. https://doi.org/10.3989/revindias.2021.012.

${ }^{1}$ helen.osorio@ufrgs.br, ORCID iD: https://orcid.org/0000-0003-2705-7958

2 jlmartiren@hotmail.com, ORCID iD: https://orcid.org/0000-0002-0826-2879 de uso y distribución Creative Commons Reconocimiento 4.0 Internacional (CC BY 4.0). 
¿UN ESPACIO RIOPLATENSE AMPLIADO? ANÁlisis DE UNA ECONOMÍA AGRARIA EN EL SUR DE Brasil (Triunfo y Santo Amaro, 1784-1849)

De manera análoga a las interpretaciones sobre la historia del mundo rural rioplatense tardocolonial e independiente, tradicionalmente se había asociado a la frontera meridional del imperio portugués en América - en parte de lo que actualmente se conoce como el estado de Rio Grande do Sul, Brasilcomo un espacio de grandes latifundistas y escasos pobladores. Se trataba de una visión tan esquemática y simplista, como simbólica: la entonces Capitanía de Rio Grande de São Pedro sentaba sus bases económicas sobre la producción pecuaria en grandes estancias, que utilizaban en mayor medida peones con ingentes aptitudes para las lides camperas ${ }^{3}$. La agricultura, según esta interpretación, era totalmente subsidiaria de la ganadería, y había sido promovida particularmente por los inmigrantes azorianos establecidos en el territorio desde mediados del siglo XVIII. Asimismo, y con una fuerte tendencia a reforzar el nacionalismo luso-brasileño, estos trabajos habían desconsiderado la amplia presencia de esclavos en la sociedad riograndense del período 4 .

Sin embargo, desde la década de 1990, estas ideas comenzaron a ser contestadas por nuevos trabajos, que aportaron un sólido anclaje documental y otras perspectivas teóricas y metodologías de análisis. Ello surgió, en parte, de una serie de investigaciones que habían redimensionado los estudios de historia agraria brasileña desde los años $1980^{5}$. Pero también, y sobre todo, de la renovación historiográfica que en esa misma década estaban atravesando los estudios sobre el sector agrario en el Río de la Plata, marcado por características similares a las que experimentaría la economía agraria del sur de Brasil ${ }^{6}$. Se dio

${ }^{3}$ El territorio de lo que actualmente se conoce como estado de Rio Grande do Sul, en el extremo meridional brasileño (limitando al sur y suroeste con Uruguay y al oeste con Argentina) tuvo distintas denominaciones a lo largo del período analizado. Hasta 1760 se lo conocía como «Continente de Río Grande». Ese mismo año pasó a ser Capitanía de Rio Grande de São Pedro, dependiente de la de Río de Janeiro. En 1807 logró su autonomía, y se pasó a llamar «Capitanía de Rio Grande de São Pedro do Sul». Finalmente, en 1821, con el inicio del proceso independentista que se materializaría en 1822, se transformó en «Provincia de São Pedro do Rio Grande do Sul». Dado que el período analizado en este trabajo incluye a las tres denominaciones, en adelante utilizaremos el nombre Capitanía de Rio Grande o bien Rio Grande de São Pedro para referirnos a dicho espacio.

${ }^{4}$ Algunas posiciones de estas visiones canónicas se encuentran en las siguientes obras: Borges Fortes, 1999. Salis Gulart, 1985. Spalding, 1953.

5 Sería imposible aquí por cuestiones de espacio citar todos los trabajos. Véase, entre otros, Almeida, 1994. Castro, 1987. Fragoso, 1992. Florentino, 1993. Faria, 1998.

${ }^{6}$ En particular, se destacan en esta línea los trabajos de Garavaglia, Gelman, Amaral, Mayo, Fradkin, Brown, Djenderedjian, Salvatore. Síntesis muy completas sobre estos avances en Gelman y Garavaglia, 1995. Fradkin, 2006. 
cuenta así de una realidad productiva y fundiaria bastante más compleja, que permitió matizar el esquema maniqueo que había primado en las interpretaciones tradicionales. Las investigaciones que afloraron en este nuevo contexto pusieron el acento en etapas clave. Por un lado, en el período tardocolonial (ca. 1760-1822), mostrando que el mundo rural riograndense combinaba en gran medida producción pecuaria con amplios nichos de agricultura, practicada no sólo por pequeños labradores — propietarios de la tierra o simples ocupantes precarios-, sino también por estancieros o hacendados. Enfatizaron a su vez que el trabajo esclavo, asociado generalmente al auge de los saladeros que tuvo lugar desde la década de 1810 en dicho espacio, ya había sido un componente fundamental en esa estructura productiva desde el período colonial. Es decir, encontraron un panorama con muchas semejanzas al del espacio rioplatense ${ }^{7}$. Por otro, abordaron todo el período independiente prerepublicano (1822-1889), analizando variables clave como los mercados de tierras, el proceso de expansión de la frontera, el crecimiento de la producción pecuaria, la colonización agrícola y el auge de la industria de saladeros ${ }^{8}$.

De todos modos, este promisorio panorama historiográfico dista aún de ser completo, por dos motivos: por un lado, debido a que muchos distritos de aquel espacio no han sido analizados en detalle. Y por otro, porque todavía no se han emprendido investigaciones a más largo plazo, esto es, que aborden en un mismo marco de análisis el período colonial y el pos independiente. Un estudio de esta factura sería muy relevante, y.a que al igual que en el Río de la Plata donde la atlantización de la economía y el quiebre revolucionario operaron como clivajes fundamentales en el gran expansión de la ganadería luego de 1810 - , en el sur de Brasil tuvieron lugar destacadas transformaciones socioeconómicas en la misma época, ligadas a similares patrones de producción.

En tal sentido, el presente artículo pretende cubrir esa laguna, mediante el análisis de un particular espacio de la Capitanía de Rio Grande de São Pedro, las freguesias (parroquias) de Triunfo y Santo Amaro, entre 1790 y $1849^{9}$. Se

${ }^{7}$ Una interesante comparación entre la economía agraria del Río de la Plata y de la Capitanía de Rio Grande en Osório, 1999.

${ }^{8}$ Pionera en este sentido fue la tesis de Paulo Zarth, que analizó el proceso de modernización de la economía rural riograndense y el proceso de emergencia del capitalismo local. Véase Zarth, 2002. Una síntesis sobre los estudios posteriores que siguieron en parte su línea de investigación en Farinatti, 2017.

${ }^{9}$ El término freguesia fue el más utilizado en las capitanías de Brasil para referirse a la organización eclesiástica del territorio. En el caso de Rio Grande de São Pedro, la escasez de capillas filiales a las iglesias matrices hizo que el término freguesia se convirtiese, en la práctica, en sinónimo de pueblo o de un centro urbano con su hinterland rural. Por tanto, tuvieron una finalidad religiosa, y a la vez alcance sobre la organización del territorio. Sobre el tema 
trata de dos casos de peso geográfico y económico, ya que no sólo su establecimiento tuvo una importancia estratégica en el poblamiento de la frontera meridional portuguesa en América, sino que a la vez experimentaron un fuerte crecimiento de la agricultura en el período colonial y de la industria de saladeros desde la década de 1820 . Resulta, por tanto, un espacio rural muy relevante para analizar, ya que se replicaron allí tres grandes características de la economía agraria riograndense (esto es, pecuaria, agricultura e industria de tasajo), mucho más ligadas al Río de la Plata que a otras regiones del sudeste o nordeste brasileños, donde la economía fue marcada por una estructura agraria más compleja y por la presencia de plantations ${ }^{10}$. En cuanto al análisis, buscaremos evidenciar distintas variables relacionadas con la evolución de esa economía agraria. Específicamente, se buscan mensurar los cambios y continuidades en la ganadería, la agricultura y en las estrategias de producción.

La hipótesis que guiará nuestro trabajo supone que, al igual que en el espacio rioplatense, la economía del extremo sur de Brasil tuvo una significativa expansión de la ganadería en el período colonial, que fue al mismo tiempo acompañada por una acentuada actividad agrícola, sobre todo de trigo para exportación. Sostiene asimismo que las estrategias de inversión y los patrones productivos estuvieron directamente ligados al comportamiento de la demanda en el comercio atlántico, evidenciando así una gran versatilidad para adaptarse a los contextos de contracción de la oferta en los puertos rioplatenses ${ }^{11}$.

Para la construcción de la evidencia nos valdremos de dos fuentes principales, frecuentemente utilizadas por la historiografía rural brasileña (y en particular, por los trabajos enfocados en el espacio riograndense). La primera es la Relação de Moradores de 1784, un censo de carácter oficial levantado en todos los campos del entonces «Continente de Rio Grande». Dicha fuente incluye listados nominales de la totalidad de los productores rurales, con detalles específicos sobre las formas de acceso y tenencia de la tierra, composición de los rebaños (vacunos, equinos, mulares y ovinos) y tipificación de su actividad (criador, labrador, productor mixto, u otras actividades). A pesar de que no existen registros similares completos para otros períodos, resulta una

para Río Grande, véase Osório, 2015: 69-70. Sobre la organización eclesiástica y administrativa en de la campaña en el Río de la Plata, véase Barriera y Fradkin, 2014. Canedo, 2016.

${ }_{10}$ Algunos estudios clásicos al respecto: Fragoso, 1992. Florentino, 1997. Mattos, 1998. Barickman, 2003.

${ }^{11}$ Desde inicios de la década de 1780, las exportaciones de Rio Grande abastecieron con tasajo, trigo, cueros y sebo a los de Río de Janeiro, Bahía y Pernambuco. Series sobre volúmenes comercializados, destinos y composición de las exportaciones desde la Capitanía de Rio Grande en: Santos, 1983: 89-153. Osório, 1999: 163-198. Menz, 2006: 93-111. Berute, 2011: 47 y ss. 
fuente de particular interés, ya que permite establecer un primer panorama de ese espacio rural a fines del siglo XVIII ${ }^{12}$. El segundo corpus documental a utilizar para elaborar la evidencia son los expedientes sucesorios (o también llamados inventarios post-mortem), que por su estado de conservación han permitido sustanciales avances historiográficos sobre la región, y han sido la base (junto a los registros parroquiales) de la mencionada renovación de la historia agraria en el sur de Brasil y en el espacio rioplatense. Es importante apuntar que la fuente no se encuentra exenta de problemas - sobre todo de representatividad de la muestra-, aunque permite realizar análisis a mediano y largo plazo sobre distintas variables económicas (composición de la riqueza, distribución, medios de producción, procesos de acumulación, entre otros). En lo que respecta a su sistematización, trabajaremos con un total de 114 inventarios, que abarcan el período 1790-1849, y corresponden a la totalidad de expedientes con bienes rurales identificados para ambas freguesias durante el período ${ }^{13}$. Agruparemos los resultados por décadas, comenzando desde 1790, y culminando el análisis en 1849, con lo cual no sólo analizaremos los patrones productivos del período colonial, sino también la expansión ganadera desarrollada en la década de 1820 y los efectos de la guerra sobre la economía riograndense, evitando así el simbólico corte temporal generado por la independencia de Portugal en 1822.

El caso: las freguesias de Triunfo y Santo Amaro y una aVanZada hacia EL OESTE

Desde el siglo XVII, la Corona portuguesa inició una avanzada sobre sus dominios meridionales, buscando llegar hasta el Río de la Plata. La fundación de Colonia del Sacramento en 1680, y del presidio (fortificación militar) de

12 Es de destacar que para algunos distritos de la Capitanía de Rio Grande (Cai o Viamão...) también se realizaron censos similares en 1797. Al respecto, véase Kühn, 2006: 191.

${ }^{13}$ La muestra incluye a la totalidad de inventarios que incluían bienes rurales disponibles para las freguesias de Triunfo y Santo Amaro, depositados en el Arquivo Público del Estado de Rio Grande do Sul, Porto Alegre. El marco temporal abarca desde 1790 a 1849. Como veremos más adelante, la antigua freguesia de Triunfo, establecida a mediados de la década de 1750, se iría desmembrando durante la segunda mitad del siglo XVIII, de modo que solo tomamos en el análisis los dos distritos más próximos del territorio primigenio: Triunfo y Santo Amaro. Vale destacar asimismo que es probable que la muestra no incluya el total de inventarios levantados efectivamente en dichos distritos, ya que para el período anterior a 1833, momento en que Triunfo pasa a tener administración propia, algunos inventarios de estas localidades se encuentran dispersos (y sin catalogar) en las comarcas de Porto Alegre, Rio Pardo y Rio Grande, lo cual hace extremamente difícil localizarlos. 
Rio Grande en 1737, se habían dispuesto como enclaves estratégicos para la ocupación de ese territorio, por entonces llamado «Continente de Rio Grande». Si bien Colonia fue entregada a la Corona española luego del Tratado de San Ildefonso en 1777, Rio Grande, luego de atravesar una ocupación española entre 1763 y 1776, logró asentarse. Su posicionamiento en el canal de la desembocadura de la Laguna dos Patos con el océano Atlántico, le permitía a los portugueses el dominio sobre una extensa red hidrográfica y a su vez poner un freno al avance español desde las tierras de la Banda Oriental. Corregía asimismo el error estratégico cometido al emplazar aquella plaza $(\mathrm{Co}-$ lonia), en tanto no se ubicaba en una posición tan avanzada y podía ser mejor resguardada militarmente, con menores costos ${ }^{14}$.

Aunque el avance no sólo se limitaba al núcleo del fuerte de Rio Grande; para la década de 1730 varias familias de la villa de Laguna (en el actual estado de Santa Catarina), hasta entonces la población lusa más austral en América, habían comenzado a establecerse sobre los "campos de Viamão», una extensa área que abarcaba prácticamente todo el territorio septentrional del «continente». Este proceso iría profundizándose en las décadas siguientes, sobre todo mediante la llegada de habitantes de otras capitanías de Brasil y de inmigrantes oriundos de las Islas Azores que se asentaron en esas tierras desde la firma del Tratado de Madrid en $1750^{15}$.

La expansión demográfica y territorial generó la necesidad de establecer nuevas poblaciones, que se llevaron adelante mediante la instalación de parroquias o iglesias matrices, denominadas freguesias en la administración portuguesa ${ }^{16}$. La primera allí creada, en 1747 , fue la de Viamão, a partir de la cual comenzó un proceso de poblamiento hacia el oeste siguiendo las márgenes del río Jacuí. La ocupación de las tierras se hacía a través de la concesión de sesmarias y datas por parte de la Corona portuguesa, pero también mediante posesiones informales ${ }^{17}$. De esta manera, en forma progresiva se fue abriendo el camino para la instalación de numerosos sesmeiros en tierras allende a aquel cauce de agua, en su mayoría azorianos. Para 1754, ya con un número considerable de pobladores, se requirió la construcción de una parroquia, que quedaría concluida dos años más tarde. Con el nuevo edificio

14 Bertulini, 1985: 35. Hameister, 2002. Comissoli, 2011: 45 y ss.

${ }^{15}$ Los militares adquirirían en este proceso un peso destacado por su rol en el afianzamiento territorial portugués en una región en constante conflicto. Al respecto, véase Osório, 1999. Zarth, 2002.

${ }_{16}$ Sobre el proceso de poblamiento de los inmigrantes azorianos y su posterior instalación en Viamão, Porto Alegre, Taquari y Rio Pardo, véase Kühn, 2006. Hameister, 2005. Barroso, 2002.

17 Sobre la ocupación de tierras en Río Grande, véase Osório, 1990. Kühn, 2008. 
construido, se dispuso definitivamente la formación de una nueva freguesia, denominada Nosso Senhor Bom Jesus de Triunfo, que se adicionaba a las otras dos ya existentes, de Rio Grande y Viamão ${ }^{18}$.

\section{MAPA 1. EXTENSIÓN TERRITORIAL APROXIMADA DE LAS FREGUESIAS DE Triunfo y SANTo Amaro (ca. 1801)}

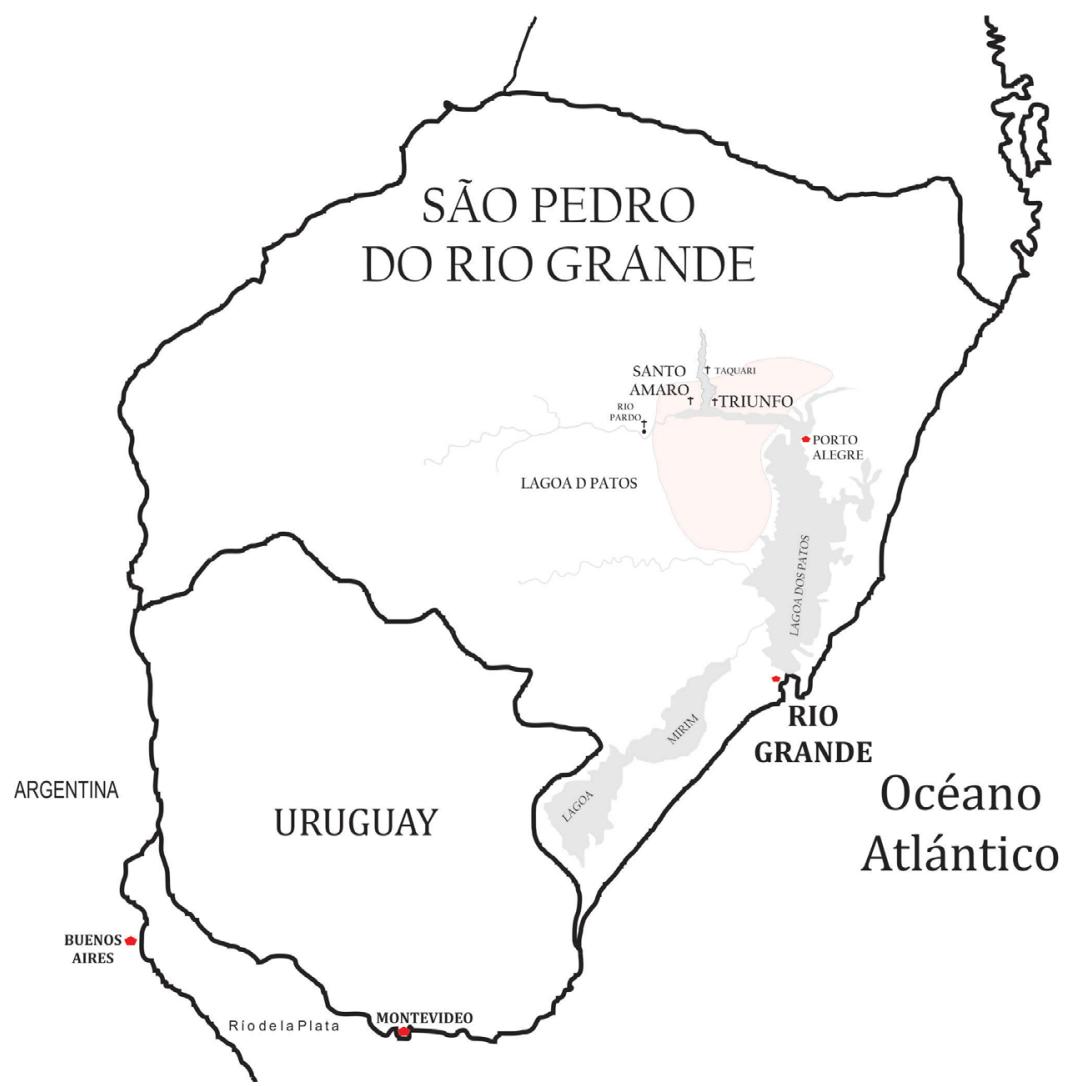

Fuente: elaboración propia de los autores a partir de mapas con divisiones territoriales de 1801 (Biblioteca Digital Luso-Brasileira, https://bdlb.bn.gov.br/acervo/handle/20.500.12156.3/21205); y de límites y fronteras de 1847 (Biblioteca Nacional de Brasil, Río de Janeiro, http://objdigital.bn.br/objdigital2/acervo_digital/div_cartografia/cart67925/cart67925.htm).

18 Vale destacar que para 1780, más del $60 \%$ de los productores y ocupantes de este espacio había nacido en las Islas Azores. Al respecto y también en relación a los antecedentes sobre la fundación de Triunfo, véase Fabrício, 1947. Kühn, 2006. Volkweis, 2011. Alvim, 2012. 
Triunfo emergió así como la primera avanzada demográfica hacia el oeste desde los campos de Viamão, alcanzando en sus inicios una superficie estimada superior a los $18.000 \mathrm{~km}^{2}{ }^{19}$. El espacio ocupado era muy amplio y difuso: en su parte meridional abarcaba desde el lago Guaiba hasta el río Camaquã; en la parte central corría sobre ambas márgenes del río Jacuí, y en la sección septentrional iba desde el río Caí hasta el Rio Dos Sinos. Sus tierras recorrían desde las planicies de la Laguna dos Patos, hasta el pie de lo que actualmente se conoce como Serra Gaúcha. Es decir, existía una diversidad orográfica y edafológica muy marcada, con abundancia de tierras con cobertura vegetal más propias para la cría del ganado (el primer distrito) y las tierras al norte del río Jacuí, con terrenos más accidentados y mayor presencia de florestas ${ }^{20}$. Esta cuestión, como veremos más adelante, se verá reflejada en la evolución económica del espacio analizado.

También llamada Freguesia Nova, Triunfo (que por entonces incluía a Santo Amaro) tuvo en sus inicios un desarrollo lento por la marginalidad de su ocupación, aunque poco a poco su posicionamiento estratégico la convirtió en un punto de referencia para unir a los habitantes de varias sesmarias que habían sido concedidas en derredor ${ }^{21}$. Este proceso fue acelerado también con la invasión de Rio Grande por las tropas españolas dirigidas por el gobernador de Buenos Aires en 1762, hecho que no sólo incrementó la concesión de tierras en dicha zona sino que también hizo que muchos de los habitantes de la villa de Rio Grande se instalaran en Triunfo. Se generó así un aumento de las unidades productivas, por lo que el territorio se iría desmembrando ${ }^{22}$. La primera freguesia en desprenderse fue la de Rio Pardo (en calidad de capela curada en 1762, y como freguesia siete años más tarde), seguida por Taquari en 1765 , y posteriormente por Santo Amaro, en $1773^{23}$. Como veremos más adelante, según el

19 Según datos estimados por Fabrício, 1947: 230.

20 Así lo demarcaban los censistas de la Relación de Moradores de 1784: «O primeiro Distr. Pertenecente ao Capm. Evaristo Pinto Bandeira é da parte meridional do Rio Guahyba e compreende até as margens do Rio Camaquã; o segundo pertencente ao Capm. Custodio Ferreira Guimarães é desde a margem septentrional do Rio Guahyba até a do Rio dos Sinos, tudo da Freguesia de Bom Jesus de Triunfo», Relação de Moradores, Arquivo Histórico do Rio Grande do Sul, Porto Alegre, Fondo Fazenda, F.1198A, Freguesia de Triunfo, f. 61.

${ }^{21}$ Alvim, 2012: 10.

22 Sobre el proceso de formación de freguesias durante el período colonial en Rio Grande de São Pedro véase Osório, 2015: 75.

${ }^{23}$ Osório, 2015: 75. Es de destacar que en nuestro estudio no consideramos a los territorios que pasaron a comprender las freguesias de Rio Pardo y Taquari, debido a que tuvieron 
censo de 1784, las freguesias de Triunfo y Santo Amaro nucleaban el 15 $\%$ de los productores rurales y casi el $25 \%$ del total de ganado que pastaba en toda la Capitanía de Rio Grande. El crecimiento demográfico también fue constante en ese contexto: los 1.997 habitantes que poblaban ambas freguesias en 1780 pasaron a ser 4.798 en 1802, alcanzando el 13 $\%$ de la población total de la mencionada Capitanía ${ }^{24}$.

Para el cambio de siglo, Triunfo y Santo Amaro habían logrado un destacado lugar en la economía agraria del extremo meridional brasileño. A su vez, desde la década de 1810 impulsaron su crecimiento mediante el establecimiento de numerosos saladeros sobre las márgenes del río Jacuí, vía de comunicación con Porto Alegre, y por su intermedio, a la barra del puerto atlántico de Rio Grande ${ }^{25}$. Estos establecimientos de producción de carne salada en Triunfo y Santo Amaro le darían una nueva dimensión a la economía local por lo menos hasta el comienzo de la denominada Revolución Farroupilha $(1835-1845)^{26}$, cuando entraron en franca decadencia y perdieron terreno con el núcleo charqueador originado alrededor de Pelotas ${ }^{27}$. Esa dinámica convierte a ambos casos en objetos de estudio muy interesantes para entender la evolución económica del sur de Brasil.

UnA PRIMERA RADIOGRAFÍA: LA «RELAÇÃO DE MORADORES》 DE 1784

En 1784, el Proveedor de la Fazenda de Rio Grande, Diego Osório Vieira, recibió la orden de realizar un censo de los pobladores que tenían «campos y animales en el Continente [de Rio Grande]» ${ }^{28}$. Dicha disposición se materializó en un registro de productores rurales llamado «Relação de Mo-

patrones de desarrollo productivo y geográfico muy diferentes. Sobre estos distritos, véase: Carvalho, 2002. Christillino, 2004.

${ }^{24}$ Cálculos propios elaborados a partir de datos tomados de Santos, 1983: 35-36. Estado de Rio Grande do Sul, 1981: 50.

${ }^{25}$ Osório, 2000.

${ }^{26}$ La Revolución Farroupilha fue un enfrentamiento bélico entre Ejército imperial y fuerzas comandas por un sector de los estancieros riograndenses, que tuvo lugar entre $1835 \mathrm{y}$ 1845. Los efectos de la guerra fueron muy negativos sobre la economía local, en particular entre 1835 y 1838. Sobre este punto, véase Leitman, 1979. Berute, 2011. Un análisis desde la historia política en Guazzelli, 1998.

${ }^{27}$ Abundan testimonios de viajeros de época que describen la crisis de la industria saladeril en este espacio. Faltan sin embargo estudios que den cuenta más pormenorizadamente de esta coyuntura. Al respecto véase Marques, 1987. Sobre el desarrollo de la industria saladeril en Pelotas, véase Vargas, 2016.

${ }^{28}$ La traducción es nuestra. Citado de Osório, 1999: 65. 
radores», que ha resultado un documento fundamental para estudiar el mundo rural de la Capitanía de Rio Grande durante el período tardocolonial ${ }^{29}$. En efecto, este censo fue una de las fuentes más utilizadas para echar por tierra con las visiones tradicionales, dando cuenta de la existencia de un mundo rural más complejo, en el cual había estancieros y pastores que no sólo criaban, sino que también labraban; existían labradores que, además de ser mayoría, contaban con pequeños rebaños, y a la vez los comerciantes también estaban insertos en la cadena de producción mediante la inversión en charqueadas ${ }^{30}$.

Más allá de estas contribuciones, es importante avanzar en el estudio específico de algunos distritos clave, dado que los datos agregados en general suelen disimular las particularidades propias de cada espacio. Por ello presentamos a continuación los resultados de dicho censo para las freguesias de Triunfo y Santo Amaro, con la intención de brindar un panorama de la economía agraria local a fines del siglo XVIII. Nos centraremos específicamente en tres variables que la fuente permite analizar: la cantidad de productores, la actividad que desarrollaban y el stock en ganado declarado. Adicionaremos también al análisis los datos generales para la Capitanía de Rio Grande, procesados por Osório (1999). Estos últimos nos permitirán no sólo ver en perspectiva las características propias de ambas freguesias, sino también estimar el peso que ambos espacios tenían sobre la economía agraria riograndense en general.

${ }^{29}$ Se trata de una fuente ampliamente utilizada. Entre los trabajos más minuciosos y detallados se destacan los de Helen Osório, Fábio Kühn, Tiago Gil, Luciano Gomes, Sandra Roth Eckhardt. El trabajo de Osório procesó la totalidad de los datos de los documentos originales disponibles en el Arquivo Nacional, situado en Río de Janeiro. El de Kühn, con una impronta más social, ha trabajado con los distritos ubicados en Viamão, Anjos y Triunfo. El de Gil analizó varios de los distritos de los Campos de Viamão, entre ellos Triunfo y Taquari, aunque no en profundidad. Gomes y Eckhardt, por su parte, pusieron el foco en los pequeños productores de Porto Alegre y Taquari, respectivamente. Véase Osório, 1999. Kühn, 2006. Gil, 2009. Gomes 2018. Eckhardt, 2017.

${ }^{30} \mathrm{Al}$ respecto, véase Osório, 2004. 


\section{Tabla 1. Los productores rurales de Triunfo y Santo Amaro según su ACTIVIDAD DECLARADA EN LA «RELAÇÃO DE MORADORES», 1784}

\begin{tabular}{|c|c|c|c|c|c|c|c|c|c|}
\hline & \multicolumn{4}{|c|}{ Total nominal } & \multicolumn{5}{|c|}{ Porcentajes } \\
\hline & \multicolumn{2}{|c|}{ Triunfo } & \multirow{2}{*}{$\begin{array}{c}\text { Santo } \\
\text { Amaro }\end{array}$} & \multirow{2}{*}{$\begin{array}{c}\text { Capitanía } \\
\text { de Rio } \\
\text { Grande }\end{array}$} & \multicolumn{2}{|c|}{ Triunfo } & \multirow{2}{*}{$\begin{array}{c}\text { Santo } \\
\text { Amaro }\end{array}$} & \multirow{2}{*}{$\begin{array}{l}\text { Triunfo } \\
\text { y Santo } \\
\text { Amaro }\end{array}$} & \multirow{2}{*}{$\begin{array}{c}\text { Capitanía } \\
\text { de Rio } \\
\text { Grande }\end{array}$} \\
\hline & 1er Dist & 2do Dist & & & 1er Dist & 2do Dist & & & \\
\hline Criador & 74 & 22 & 28 & 817 & 90 & 31 & 33 & 52 & 52 \\
\hline Labrador & 0 & 19 & 6 & 220 & 0 & 26 & 7 & 10 & 14 \\
\hline $\begin{array}{l}\text { Criador y } \\
\text { labrador }\end{array}$ & 6 & 5 & 12 & 132 & 7 & 7 & 14 & 10 & 8 \\
\hline $\begin{array}{l}\text { Más } \\
\text { labranza que } \\
\text { cría }\end{array}$ & 0 & 20 & 39 & 70 & 0 & 28 & 45 & 25 & 4 \\
\hline Otros & 0 & 3 & 0 & 72 & 0 & 4 & 0 & 1 & 5 \\
\hline $\begin{array}{l}\text { No } \\
\text { informados }\end{array}$ & 2 & 3 & 1 & 253 & 3 & 4 & 1 & 2 & 17 \\
\hline TOTAL & 82 & 72 & 86 & 1.564 & 100 & 100 & 100 & 100 & 100 \\
\hline
\end{tabular}

Fuente: elaboración propia en base a la Relação de Moradores, Arquivo Histórico do Rio Grande do Sul, Porto Alegre, Fondo Fazenda, F.1198A, Freguesia de Triunfo, ff. 33-94. Los datos generales para la Capitanía de Rio Grande fueron tomados de Osório, 1999: 68.

Un primer aspecto a remarcar de la tabla es que se trataba de un espacio relativamente equilibrado en cuanto a la cantidad de productores: en el primer distrito de Triunfo se registraron 82 jefes de unidades, de los cuales el $38 \%$ fueron catalogados en la fuente como «Fazendeiros maiores» (grandes estancieros); el $35 \%$ como «Fazendeiros menores» (estancieros de menor tamaño) y el restante $27 \%$ como «agregados» (es decir, aquellos que ocupaban tierras en las «fazendas maiores y menores» sobre la base de diferentes acuerdos con los propietarios). En el segundo distrito, por su parte, localizado sobre las márgenes septentrionales del río Jacuí, se censaron 72 productores; allí la fuente no realiza divisiones según el tamaño de la unidad, aunque sí destaca que 13 de éstos se encontraban en «chacras sin títulos de propiedad». En Santo Amaro se contabilizaron 86 agentes; en dicho registro tampoco se incluyeron detalles específicos sobre el tipo de explotación. En suma, ambas freguesias contaban con un total de 240 productores, equivalentes al $15 \%$ del total de la Capitanía ${ }^{31}$.

31 Esa cantidad de productores en ambas freguesias va en línea con el peso demográfico que tenían en general, que según el censo de 1780 era del $11 \%$ (esto es, 1.997 habitantes sobre un total 17.923 para toda la Capitanía). Al respecto, véase Santos, 1983: 35. 
Por lo demás, la homogeneidad en términos cuantitativos se desdibuja al analizar las actividades rurales, ya que se evidencian importantes diferencias en el seno de ese espacio, marcadas en particular por la morfología de las unidades de explotación. Así, mientras en el primer distrito de Triunfo sólo en el 7 \% de las unidades censales se menciona la presencia de labradíos (en ningún caso como actividad exclusiva), en el segundo distrito y en Santo Amaro la relación es inversa: no sólo las actividades mixtas (cría de ganado y sementeras) tuvieron em ambas un peso importante, sino que eran predominantes las actividades agrícolas $^{32}$. Ergo, es evidente que el primer distrito era prácticamente ganadero, prevalecían allí las grandes unidades de explotación y la agricultura parecía ser residual. Ahora bien, al comparar nuevamente con el total de la Capitanía, los resultados agregados de ambos espacios en conjunto parecen ser bastante homogéneos en lo que respecta a cantidad de criadores, pero surgen algunas diferencias derivadas sobre todo del peso que los agricultores tenían en Santo Amaro y, en menor medida, del segundo distrito de Triunfo.

Más allá de que la fuente no ofrezca datos de agricultura, se han conservado algunos registros generales de la década de 1780 sobre cultivos de trigo en la Capitanía que refuerzan en cierto sentido la tabla anterior, dando cuenta del fuerte peso que tenían la producción triguera en Santo Amaro y en el segundo distrito de Triunfo. Según datos recabados por Medeiros dos Santos, en 1781 y 1782, Santo Amaro y Caí (parte del segundo distrito de Triunfo) recolectaban juntos el 14 y el $18 \%$ del total del trigo de la Capitanía ${ }^{33}$.

En cuanto a la ganadería, la fuente sí aporta abundante información. Es de destacar en este punto que si ambas freguesias abarcaban el $15 \%$ del total de los productores de la Capitanía y entre el 14 y el $18 \%$ del trigo trillado, en lo que respecta a la proporción del ganado sobre el total el lugar de ambos distritos era aún mayor, en el orden del $26 \%$. Esto se debía a la impronta ganadera que tenía Triunfo (y sobre todo el primer distrito), donde se declaraba la existencia de un stock de 125.155 animales (incluyendo reses vacunas de cría, bueyes, caballos, yeguas, mulas, burros y ovejas), con un gran predominio del ganado bovino. En Santo Amaro, por su parte, las tenencias eran menos considerables (llegando a 53.147 animales), y a pesar de que contaba

${ }^{32}$ Los resultados del segundo distrito de Triunfo y los de Santo Amaro son muy similares a los que encontró Helen Osório para el total del Continente (1.564 productores). La autora registra que el $65,1 \%$ de los pobladores vivían de actividades agrícolas o mixtas. En nuestro caso, encontramos que de las 86 unidades censales del Segundo Distrito, el $67 \%$ declaraba vivir de labranza exclusivamente o combinando agricultura con cría de animales, mientras que en Santo Amaro, sobre 82 pobladores, la cifra se eleva a 73 \%. Véase Osório, 2004: 78.

${ }^{33}$ Santos, 1983: 96-97. 
también con preeminencia de rebaños bovinos (57\% del total), el lugar de los equinos era significativo.

El gran dinamismo ganadero de ambos espacios no resulta un dato sorprendente: debe tenerse en cuenta que entre 1780 y 1800 toda la Capitanía inició un fuerte crecimiento de la pecuaria, sobre todo en tierras de frontera. Este ciclo fue alimentado por la demanda de dos mercados principales: por un lado, tres plazas atlánticas brasileñas, a las que se dirigían subproductos bovinos (cueros, charque y grasa/sebo) ${ }^{34}$; y por otro, la venta de mulares para la actividad minera (tráfico que se hacía por tierra a través de los mercados de Sorocaba) $)^{35}$. Para ese entonces, Triunfo, y sobre todo la enorme extensión de su primer distrito, ofrecía un escenario muy propicio para la multiplicación de los rebaños.

\section{Gráfico 1. Distribución de los tipos de rebaños en Triunfo, Santo Amaro} y en la Capitanía de Rio Grande

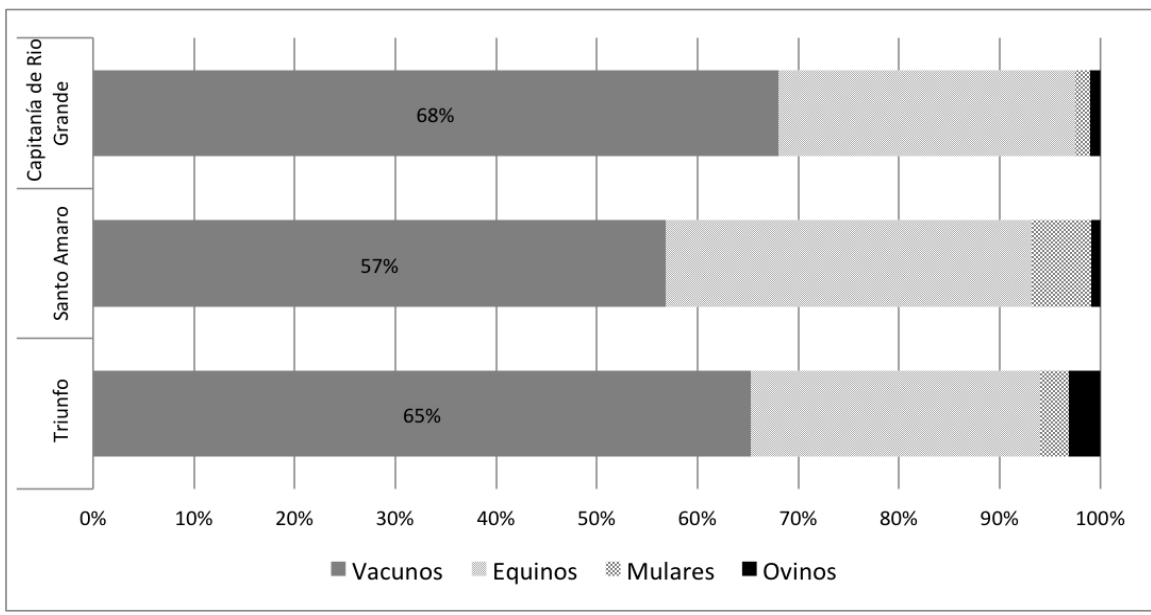

Fuente: elaboración propia en base a la «Relação de Moradores», Arquivo Histórico do Rio Grande do Sul, Porto Alegre, Fondo Fazenda, F.1198A, Freguesia de Triunfo, ff. 33-94. Los datos generales para la Capitanía de Rio Grande fueron tomados de Osório, 1999: 100.

34 Según cálculos recabados por Osório, los principales puertos de destino de las exportaciones de derivados pecuarios riograndense eran Bahía, Río de Janeiro y Pernambuco, en ese orden. Véase Osório, 2010: 195

${ }^{35}$ La expansión de la pecuaria riograndense tardocolonial ha sido ampliamente estudiada por la literatura académica. Sobre el tema, véase: Osório, 1999. Gil, 2009. 
Los datos levantados en el gráfico 1 vuelven a mostrar un panorama similar al de la tabla 1, esto es, resultados muy parejos entre Triunfo y el total de la Capitanía, y algunas diferencias con respecto a Santo Amaro. En lo que respecta a Triunfo, se nota una inversión mayoritaria en vacunos (con más del $65 \%$ del total del ganado en ambos casos), seguida por equinos (alrededor del $30 \%$ ) $y$, en menor medida, diversificada con la presencia de ganado mular (que si bien en cantidad no competían con éstos, sí aumentaban considerablemente su peso relativo en términos monetarios). En Santo Amaro, a pesar de que los vacunos lideraban el stock pecuario, se percibe un mayor peso en la cría de mulas, traducido en más ejemplares de esta especie y también en burros hechores y de los equinos, necesarios para esta práctica. Los ovinos, por lo demás, tuvieron un lugar marginal en la ganadería de la región para esa época.

En síntesis, el escenario que arroja la Relação de Moradores para el punto de inicio de este estudio (1784) es el de la coexistencia de dos grandes matrices productivas al interior del espacio: una, el primer distrito de Triunfo, de corte ampliamente ganadero, con unidades de explotación especializadas en la cría de ganado extensiva. La otra, presente en el segundo distrito de Triunfo y en Santo Amaro, estaría indicando la existencia de una combinación más pareja la ganadería con agricultura, con un peso muy importante de los sectores medios. Es destacable en este sentido que sólo el segundo distrito de Triunfo y Santo Amaro parecen condecirse con la imagen renovada del agro colonial en el Continente de Rio Grande de São Pedro.

De cualquier manera, se trata de una imagen parcial de una realidad mucho más compleja, ya que más allá de de su valía estadística, este registro no otorga más que un paneo general de ese cambiante mundo rural limitado al año 1784. Es por ello que resulta necesario complementar esta evidencia con nuevos datos que den cuenta de los distintos cambios a lo largo del tiempo. Los inventarios post-mortem resultan, en este punto, una fuente fundamental, debido a que su utilización en escala nos permite realizar un abordaje más sistemático en el largo plazo. Por consiguiente, presentaremos a continuación los resultados obtenidos de su procesamiento, a partir del cual analizaremos diversas variables productivas de la economía agraria del lugar.

El patrimonio productivo de Triunfo / Santo Amaro a través de los INVENTARIOS (1790-1849)

\section{Los medios de producción}

El registro de 1784 adelantó un cuadro interesante para las freguesias de Triunfo y Santo Amaro: en aquel particular y difuso espacio abierto al oeste de 
los campos de Viamão, muy pronto se desarrolló un esquema de producción basado en dos frentes claros. Por un lado, grandes unidades de explotación ganadera ubicadas en la amplia región meridional del río Jacuí; por otro, el distrito septentrional de Triunfo y las tierras de Santo Amaro, que combinaban medianos y grandes agentes, pero con una orientación productiva mixta.

Ahora bien, ¿se extendió ese patrón a lo largo del tiempo? ¿Cómo impactaron las distintas coyunturas mercantiles y los cambios políticos en las estrategias o realidades particulares? Desafortunadamente no existen fuentes censales fiables o comparables a lo largo del tiempo, por lo que debimos optar por otra estrategia: construir evidencia a partir del procesamiento los inventarios post-mortem para el período 1790-1849, con el objetivo de analizar no sólo el peso que tuvo la apertura comercial en la década de 1810, sino también las distintas coyunturas bélicas que afectaron el territorio riograndense durante el período. Analizaremos de este modo la evolución de los diferentes componentes del patrimonio productivo.

\section{Gráfico 2. Participación de los BIENES DE PRODUCCiÓN EN EL PATRIMONIO PRODUCTIVO TOTAL (1790-1849)}

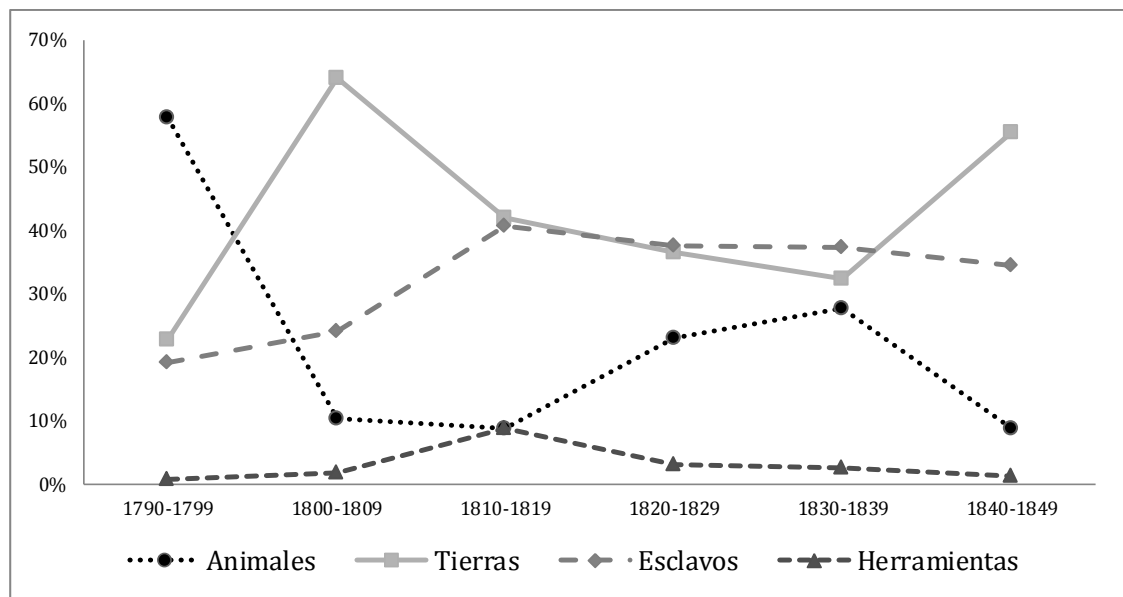

Fuente: elaboración propia en base a 114 inventarios consultados en el Arquivo Público do Estado do Rio Grande do Sul, Porto Alegre. La base incluye una muestra de 10 inventarios para el período 1790-99; 12 inventarios para el período 1800-09; 10 inventarios para 1810-19; 30 inventarios para $1820-29$; 33 inventarios para $1830-39$ y 19 inventarios para $1840-49^{36}$.

${ }^{36}$ Los inventarios fueron consultados en el APERS, Fondo Inventarios, cajas: 028.0087 (3 exps.); 004.0060 (2 exps.); 004.0062 (2 exps.); 004.0781 (1 exp.); 004.0782 (2 exps.); 
El primer eje de análisis que presentaremos a través de los inventarios será el de la evolución de las inversiones en los medios de producción en general a lo largo del período analizado. El panorama que evidencia el gráfico 2 comprueba aspectos ya conocidos de la economía riograndense, y otros, sobre los cuales aún resta profundizar. Las tendencias allí reflejadas parecen indicar tres claras etapas, que van en línea con la evolución de su economía. La primera abarca el final del siglo XVIII, y es coincidente en cierto sentido con los resultados de la Relação de Moradores de 1784: se nota el peso significativo que tiene el ganado sobre las inversiones rurales, secundado por niveles homogéneos en tierras y esclavos, e inversiones muy menores en herramientas y utillaje agrícola. Como vimos en el apartado anterior, se trata de un período de expansión geográfica, territorial y demográfica, con un lógico peso creciente de las inversiones en ganado.

La segunda etapa se abre con el cambio de siglo, y corre hasta la década de 1820. Si bien no tenemos indicadores de actividad agrícola y pecuaria para ambas décadas, sí conocemos que hubo un crecimiento muy fuerte de las exportaciones de charque y trigo (véase apéndice 3). En tal sentido, las tendencias de las inversiones sugieren una clara correspondencia con ese contexto exportador, basada en tres motivos: a) la caída en los stocks vacunos parece estar indicando un fuerte aumento de la demanda de ganado (ahondaremos más sobre esta cuestión en el siguiente apartado); b) El aumento de las inversiones en herramientas estaría sugiriendo una expansión de la agricultura; c) El incremento del peso de las inversiones en esclavos, destinados a ambas actividades, también podría estar impulsado por dicha expansión, o bien por una mayor demanda de los emergentes saladeros.

La tercera etapa, que abarca las décadas de 1820 a 1840, está signada por la gran expansión de la industria saladera. Más allá de que su existencia es anterior a la década de 1820 - de hecho, debieron haber tenido una destacada influencia en el aumento de los saldos exportables de charque durante los años 1810 - fue a partir de ese momento en que se produjo su gran despegue, con base en dos nichos principales de la Capitanía: Triunfo / Santo Amaro y Pelotas. Este incipiente desarrollo de un capitalismo productivo y mercantil generará un fuerte impacto sobre el valor de los inmuebles, el ganado y los

004.0783 (2 exps.); 004.0786 (2 exps.); 004.0821 (1 exp.); 004. 0835 (1 exp.); 004.0879 (1 exp.); 004.1002 (4 exps.); 004.1003 (5 exps.); 004.1004 (11 exps.); 004.1005 (15 exps.); 004.1006 (8 exps.); 004.1007 (7 exps.); 004.1008 (8 exps.); 004.5300 (2 exps.); 004.5305 (9 exps.); 004.5306 (8 exps.); 004.5307 (10 exps.); 004.5308 (6 exps.); 004.5313 (1 exp.); 007.0250 (2 exps.); 007.0255 (1 exp.). 
esclavos $^{37}$. Ello explica la convergencia entre estos tres activos en las décadas de 1820 y 1830, que desde luego se desdibujará en los años 1840 debido a las consecuencias de la guerra, que afectó en particular a los stocks bovinos en dicho espacio.

Los resultados no distan demasiado de los ya conocidos para Rio Grande en ese período. En lo que respecta al primer caso, los comportamientos son similares en toda la Capitanía. Este argumento se sostiene con fuerza en la información presentada en los apéndices 1 y 2, en los cuales analizamos comparativamente los datos de inversiones en ganado y esclavos en Triunfo / Santo Amaro con los recabados para otros distritos durante el período. Para el período colonial, la evidencia provista por Osório para toda la Capitanía en el período 1765-1825 y la de Gularte para el distrito de Jaguarão (localizado en la frontera con la Banda Oriental) es muy coincidente, salvo una leve diferencia en la década de 1790, donde Triunfo y Santo Amaro parecen tener ciertas particularidades. Con respecto al período posterior a la independencia (1822-1849), las comparaciones que efectuamos con el distrito de Caçapava (y parcialmente con Jaguarão) en relación a esos dos activos van muy en línea con los resultados de Triunfo ${ }^{38}$. Es decir, más allá de que Triunfo y Santo Amaro presenten altas inversiones en esclavos y construcciones por haber sido núcleos charqueadores, el comportamiento de las derivas es el mismo. Esto estaría mostrando una economía mucho más integrada de lo que se supone.

La comparación con el Río de la Plata también en este adquiere ribetes interesantes. Con respecto a Buenos Aires, y al igual que había mostrado Helen Osório, hay una notoria convergencia durante el período colonial, en especial con los distritos de la campaña bonaerense con características semejantes a las de Triunfo y Santo Amaro, esto es, departamentos de más antigua ocupación y con mayor cercanía con el puerto de Buenos Aires. Las semejanzas se basan en el hecho de que eran economías con bases estructurales

37 Sobre la evolución del valor de los esclavos, véase el apéndice 5. Sobre el ganado, véase apéndice 4. En ambos casos se nota claramente el impacto que tuvo la especialización saladera sobre los factores, el valor de los activos productivos y el precio de los bienes de exportación. Desde luego ello debió de haber afectado también al costo de vida, más si se tiene en cuenta que la carne era el bien principal en la dieta riograndense. Sobre este tema, véase Djenderdjian y Martiren, 2020.

38 Es de destacar que, más allá de la similitud en su evolución, los porcentajes sobre capital en esclavos no tuvieron el mismo peso en distritos de corte marcadamente ganaderos como Alegrete, donde Farinatti encontró proporciones mucho menores (en torno al $20 \%$ del total de la inversión) en las décadas de 1830 y 1840 . Ello se explica allí por ausencia de charqueadas y el mayor peso de la mano de obra libre. Véase Farinatti, 2007: 48. 
coincidentes: unidades productivas ganaderas y mixtas, con importantes contingentes de pequeños y medianos productores que practicaban agricultura y cría de rebaños ${ }^{39}$. Algo disímiles son los resultados que conocemos para Entre Ríos, otra provincia del espacio rioplatense, donde el predominio de las inversiones en ganado era preponderante en estancias medias ${ }^{40}$.

Pero desde la década de 1820 , el panorama cambia bastante, y la divergencia con el espacio rioplatense se hace evidente, impulsada en gran medida por una variable, la mano de obra esclavizada. Mientras el Río de la Plata se encuentra en fuerte declive luego de la disposición de la libertad de vientres en 1813, las guerras y el fin del tráfico, en Rio Grande (y particularmente en núcleos productores de charque, como Triunfo y Santo Amaro) la mano de obra esclava tuvo un fuerte crecimiento ${ }^{41}$. Los resultados en este sentido son indudables: según los cálculos de Garavaglia para el período 1816-1852, la inversión en esclavos en las estancias alcanzó sólo el $3 \%$, mientras que en Triunfo / Santo Amaro promedió el $36 \%^{42}$. En el capital ganadero las diferencias también son manifiestas, aunque deben considerarse en este punto los efectos negativos de la guerra entre 1835-1845, que tuvo mucha influencia sobre el territorio de Triunfo y Santo Amaro. En cuanto a la tierra, por lo demás, las tendencias son bastante similares, aunque con un peso mayor en el caso de Triunfo, derivado de la influencia de los saladeros en la mercantilización de este activo, y en la fuerte caída de los vacunos, que generó un aumento en el peso relativo de los otros medios de producción (Garavaglia, 1999: 711). También pudo haber afectado la diversidad geográfica allí impe-

${ }^{39}$ Los cálculos de Garavaglia para las estancias de Buenos Aires en el período 1751-1815 arrojan los guarismos siguientes en relación a los medios de producción: ganado, 55 \%; esclavos, $17 \%$; tierras y construcciones, $27 \%$; otros, $1 \%$. Datos tomados de Garavaglia, 1999: 711.

${ }^{40}$ Los porcentajes presentados por Djenderedjian para Entre Ríos presentan algunas diferencias con Triunfo y Santo Amaro. Si bien son similares en los inventarios de grandes estancieros (56\% en ganado, $23 \%$ en tierras y construcciones; $18 \%$ en esclavos y $1 \%$ en cultivos), en las estancias de menor tamaño las proporciones son distintas, ya que allí el peso de los ganados superaba el $80 \%$ en los expedientes analizados. Véase Djenderedjian, 2003: 232-233.

${ }^{41}$ Resulta muy interesante el rol que jugó el factor trabajo en el inicio de la divergencia entre Rio Grande de São Pedro y el Río de la Plata. Si bien ambos espacios ampliaron su producción ganadera y sus exportaciones de derivados pecuarios, lo hicieron con distintos mecanismos de fuerza laboral. Mientras Rio Grande profundizó la inversión en esclavos, las autoridades rioplatenses (en especial, Buenos Aires) desarrollaron diferentes mecanismos de coerción estatal para captar la mano de obra libre. Sobre este tema, véase Gelman, 1998. Amaral, 1998. Salvatore, 2018. Para Rio Grande, ver Aladren, 2012.

42 Debe destacarse, no obstante, que los altos niveles de inversión en esclavos se daban sobre todo por la presencia de saladeros, seguramente no contabilizadas en el análisis de Garavaglia, limitado sólo a las estancias. 
rante; es probable que el incremento del rubro inmobiliario sobre el patrimonio productivo se haya asentado en las posibilidades que ofrecían las planicies del primer distrito para la expansión de la pecuaria (y por ende, su integración con la economía charqueadora).

En suma, los datos presentados exhiben en parte un escenario ya descripto por la bibliografía, léase, un espacio con características similares a las del Río de la Plata durante el período colonial, y una divergencia iniciada luego de ambas independencias.

\section{El ganado y los instrumentos de labranza}

Si el análisis del patrimonio productivo en su conjunto mostró una evolución de la economía agraria muy afectada por las particulares coyunturas del período, a continuación veremos con mayor detalle el comportamiento las inversiones ganaderas y agrícolas. En cuanto al primer aspecto, buscaremos exhibir los cambios en la composición de los rebaños a lo largo del período y ver su relación con los movimientos del stock ganadero. En lo que respecta a las prácticas agrícolas, analizaremos las tenencias de utillaje agrícola y el peso que tuvieron las coyunturas económicas en las decisiones de inversión.

En el siguiente gráfico se expone la evolución de la composición de los rebaños totales durante el período analizado. Los porcentajes, como se advierte, tienen una considerable correlación con la tendencia de las inversiones en ganado expuestas en el gráfico 2. Esto es, un fuerte predominio de los vacunos en épocas de expansión de la ganadería (décadas de 1790, 1820 y 1830) y un aumento relativo de otros tipos de animales en momentos de depresión o crisis de oferta (1810 a 1820 y 1840).

Esta información permite brindar nuevas interpretaciones en relación a los efectos de las coyunturas económicas y bélicas sobre el stock pecuario. En este sentido, una cuestión a explicar es el comportamiento del ganado en las dos primeras décadas del siglo XIX. Es decir, ¿qué factor explicaría una caída en las inversiones en ganado de tal magnitud? En principio, podrían esbozarse tres explicaciones al respecto. La primera es un eventual problema de la muestra, ya que sólo conseguimos localizar 12 inventarios para la década de 1800 y 10 para la siguiente. Sin embargo, este no parece ser un limitante ${ }^{43}$.

${ }^{43}$ Véanse al respecto las derivas del gráfico del apéndice 1, donde puede apreciarse que no fue un fenómeno exclusivo de Triunfo y Santo Amaro, sino común a varios distritos de la Capitanía de Rio Grande. 
Gráfico 3. Composición de los rebaños de Triunfo / Santo Amaro EN CANTIDAD Y CAPITAL INVERTIDO, 1790-1849

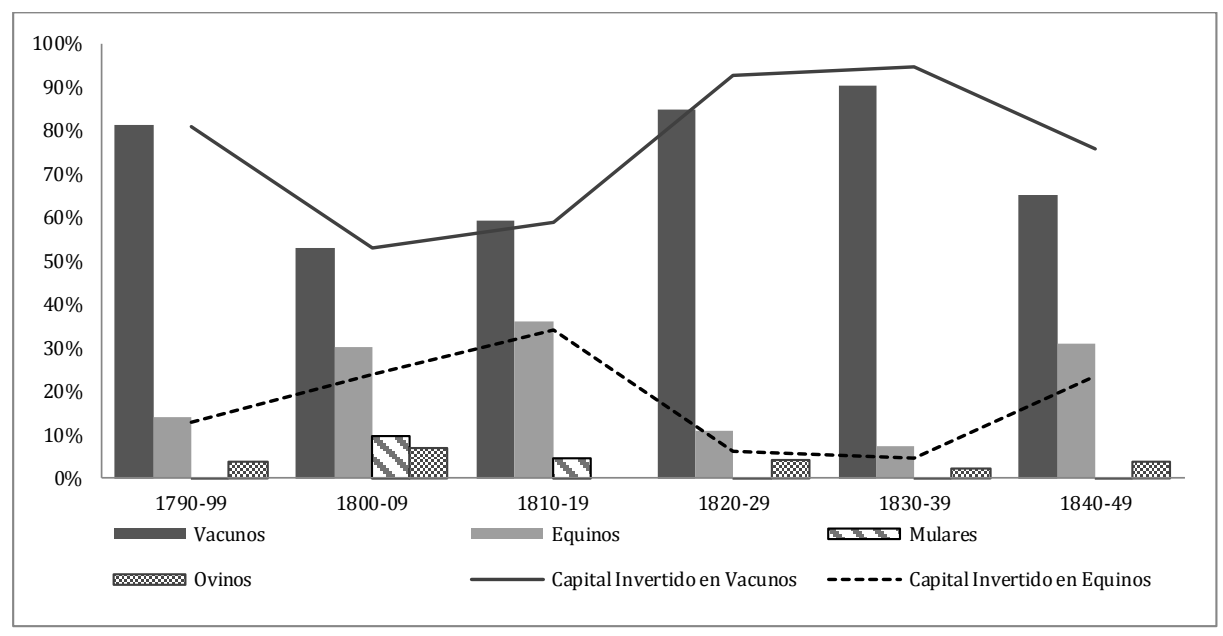

Fuente: la misma fuente que la especificada en el gráfico 2.

La segunda explicación que podemos sugerir es que el mencionado crecimiento que experimentaron las exportaciones de derivados pecuarios a inicios del siglo XIX, pudo haber generado niveles de faena más altos que los de reproducción ${ }^{44}$. Parece la más plausible si se considera que el contexto bélico propiciado por las guerras revolucionarias en el Río de la Plata había afectado su comercio exterior, algo que sin dudas fue aprovechado por la economía riograndense, que cubrió en parte la oferta rioplatense. Pero para mantener ese nivel de exportaciones, era necesario un importante un aumento de los rebaños o bien de la productividad pecuaria. Todo indica, entonces, que hubo un ciclo de fuerte faena de bovinos y ello se ve reflejado en esa tendencia decreciente en términos de capitalización. Sin embargo, hay un elemento extra que llama la atención: los precios de las reses se mantuvieron estables durante el período, tal como se puede apreciar en el gráfico 4 del apéndice. Es decir, si la fuerte demanda de ganado fue liquidando los stocks, ello debe-

44 Tal como se puede notar en el apéndice 3, el comercio exterior de Río Grande tuvo un fuerte crecimiento a inicios del siglo XIX, en particular durante la década de 1810, cuando las guerras revolucionarias y la ocupación lusa en la Banda Oriental afectan a las exportaciones rioplatenses de derivados pecuarios. Sobre este punto, véase Osório, 1999. Menz, 2007. Berute, 2011. Sobre las exportaciones rioplatenses, véase Schmit y Rosal, 1999. 
ría haberse traducido en una tendencia al alza de los precios del ganado. De todos modos, la explicación a este fenómeno parece provenir del Río de la Plata. Debe tenerse en cuenta que la década de 1810 estuvo atravesada por una fuerte coyuntura bélica; con el quiebre revolucionario iniciado en Buenos Aires en mayo de 1810, el ejército portugués inició la ocupación de la Banda Oriental. La primera invasión fue en 1811 y duró hasta 1812, cuando se retiraron parcialmente. En 1815 iniciaron una segunda avanzada y en 1817 tomaron Montevideo. Durante ese lapso, se estima que el arreo de ganado desde la Banda Oriental alcanzó enormes proporciones, lo que pudo haber frenado eventuales subas de precios en las reses ${ }^{45}$.

En este punto, es llamativo también el incremento en las existencias y el capital invertido en equinos y mulares (la producción de equinos se destinaba tanto a la venta de caballos como a complementar la cría de mulas). La explicación a este fenómeno podría haber estado ligada, por un lado, a una profundización del abastecimiento de ganado mular a otros mercados regionales brasileños, $\mathrm{y}$, por otro, por la alta demanda de equinos provocada por el inicio de período revolucionario en el Río de la Plata ${ }^{46}$. De todos modos, parece menos probable, más aún si tenemos en cuenta que el peso del total de los ganados disminuyó en relación a los medios de producción - tal como se vio en el gráfico 2- lo que indicaría que el aumento de los equinos y mulares sobre el total del stock pecuario no habría sido per se, sino debido a una brusca caída de los bovinos.

La tercera razón del declive en el stock ganadero pudo haber sido un fuerte aumento de la agricultura, a juzgar por tres variables: una coyuntura de grandes aumentos en la exportación de trigo (como se puede notar en el apéndice 3); una destacada alza de la inversión en herramientas (que alcanza el 9 $\%$ del total de capital en medios productivos) y un aumento de la inversión en bueyes de trabajo. Esta variable «agrícola» cobra más fuerza al considerar que el segundo distrito de Triunfo y Santo Amaro tenían consistentes bolsones de producción de granos en la década de 1780 , por lo que no sería ilógico que hubiera habido, al menos parcialmente, un proceso de reconversión que

45 Según datos levantados por Osório sobre las solicitudes de ingreso de ganado de la Banda Oriental luego de las mencionadas invasiones lusas, en 1812 fueron autorizadas a entrar 40.000 cabezas y en 1813, más de 77.000. También aporta testimonios de época, que estimaban en un millón los vacunos arriados desde la Banda Oriental entre 1811 y 1819. Véase Osório, 2010: 177-178.

${ }^{46}$ En el apéndice 6 puede notarse que el aumento de la cantidad y del capital en equinos estuvo impulsado más que nada por los caballos mansos (de montar), lo cual podría indicar un proceso de abastecimiento de estos animales en ese contexto de guerra. 
afectara la dimensión de los rebaños ${ }^{47}$. Indagaremos más sobre estos dos últimos puntos al final del apartado, mediante un análisis más específico de la evolución de la agricultura.

Por lo demás, las décadas de 1820 y parte de los años 1830 experimentaron una fuerte recuperación de los stocks, aunque la guerra desatada en 1835 generó una nueva disminución en las existencias, que se manifiesta de forma notoria en la década de $1840^{48}$. Lamentablemente no hay cifras de producción para dicha época, por lo que tenemos que ceñirnos a los datos del comercio exterior. Tal como se aprecia en el apéndice 3, las exportaciones se vieron muy afectadas en los primeros años del episodio bélico. No obstante, desde 1840 se inicia un ciclo de crecimiento que tendría su punto álgido en 1846, nuevamente en un contexto de problemas en el comercio exterior del Río de la Plata ${ }^{49}$. Es probable, por tanto, que esa caída en los stocks bovinos tenga en parte que ver con la expansión del comercio exterior. Es decir, una historia bastante similar a la ocurrida a inicios de siglo.

Si profundizamos aún más el análisis, y nos centramos concretamente en los bovinos, el argumento anterior cobra aún más relevancia: puede verse así que no sólo aumentó el capital en equinos y mulares, sino que también entre los bovinos ganaron mucho espacio los bueyes y las vacas lecheras (en detrimento de la inversión en vacas de cría, que cayó de manera abrupta). Esto estaría indicando que la reducción del rebaño se habría dado específicamente en el tipo de animal destinado a la faena para saladeros.

${ }^{47}$ Esta situación es coincidente con relatos de época. Sobre la agricultura en Rio Grande de São Pedro, Mawe, un inglés que llegó a Montevideo con las invasiones inglesas en 1807, y luego recorrió Brasil, afirmaba en 1808: "The climate is considered very fine, and the soil so productive, that this district may be called the granary of Brazil: the wheat grown here is shipped to all the ports on the coast where bread is used». En Mawe, 1812: 316-17. Otro relato sobre el período, aunque relativo a Triunfo es el de Henderson, datado en 1818, quien hablaba de prácticas agrícolas en ese espacio: "A Little more tan thirty-five miles to the west of Portalegre is the conserable and delightful arraial of the new parish [Freguesia Nova o Nosso Senhor Bom Jesus do Triunfo], near the mouth of the Tacoary. Its inhabitants raise wheat and cattle. About eighteen miles to the north is the parish of St. Jose [Freguesia de São José de Taquari], with a large praça or square, on which is the mother church. It was the source of the agriculture of this province, and its people are mostly descendants of the first settlers from the Azores... They began to cultivate wheat and Indian corn according to the method of their own country, and which is at this day the occupation and support of their posterity», Henderson, 1821: 120-121.

${ }^{48}$ Como puede apreciarse en el apéndice 1, las tendencias son muy parecidas en todo Río Grande; la caída del ganado en los años 1840, al igual que tres décadas atrás, no fue solo una característica de Triunfo y Santo Amaro.

49 Sobre los bloqueos al puerto de Buenos Aires durante el rosismo, véase Gelman, 2009. 
Gráfico 4. Distribución de los Rebaños bovinos en Triunfo y Santo AMARO, EN CANTIDAD DE CABEZAS Y EN CAPITAL INVERTIDO, 1790-1850

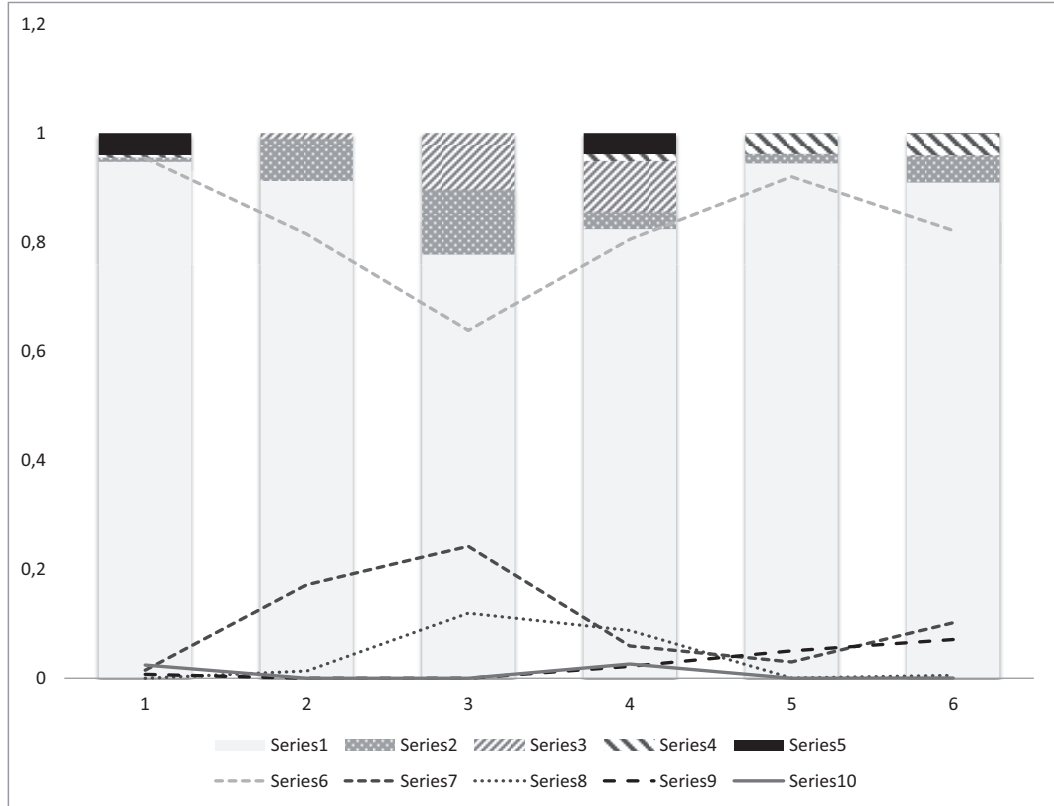

Fuente: la misma fuente que la especificada en el gráfico 2.

Por lo demás, los datos del gráfico 4 ofrecen también algunas pistas sobre la evolución de la agricultura. Tal como se ha mencionado antes, el auge exportador experimentado en las primeras décadas del siglo XIX no sólo dependió de los derivados pecuarios, sino también del trigo. El crecimiento de los saldos exportables señalaría, de alguna manera, una correlación con la producción de este cereal ${ }^{50}$.

Desde luego, el estudio de la agricultura durante el período elegido presenta un problema difícil de sortear, que es la escasez de fuentes estadísticas, por lo que su análisis sólo puede hacerse a través de datos indirectos.

${ }^{50}$ El crecimiento de la agricultura tardocolonial es un fenómeno ya probado por la historiografía. El desplazamiento de las interpretaciones tradicionales sobre la historia riograndense se basó, entre otras cosas, en el redescubrimiento de la importancia de la producción agrícola. Sobre este punto, y en particular la frecuencia de herramientas agrícolas en inventarios de productores de Rio Grande y del distrito de Jaguarão, véase Osório, 1999 y Gularte, 2015. 


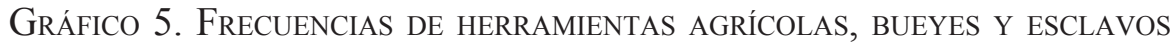 EN LOS INVENTARIOS RURALES}

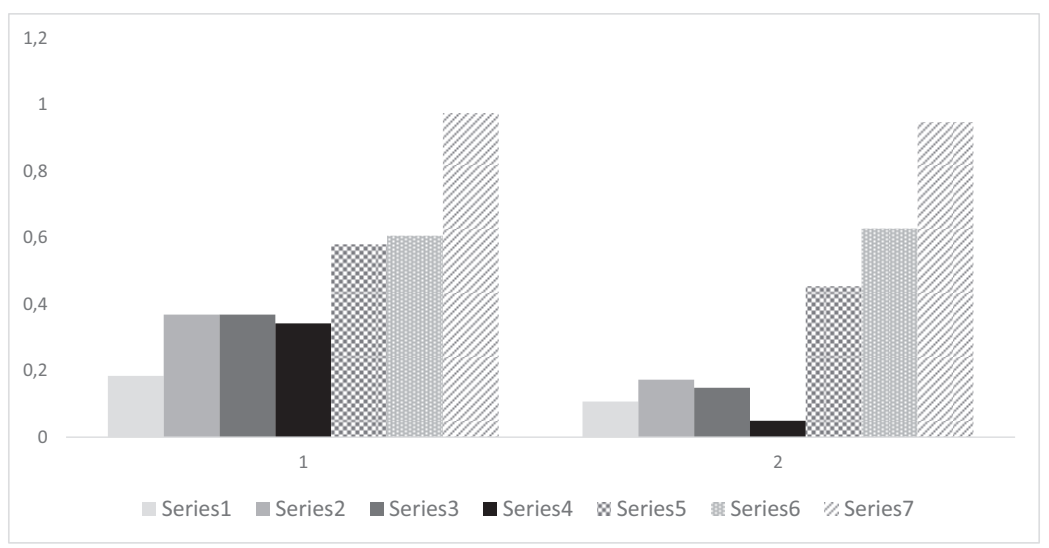

Fuente: la misma fuente que la especificada en el gráfico 2.

Este fenómeno parece tomar más fuerza si analizamos las frecuencias de aparición de herramientas y utillaje agrícola en los inventarios. Como puede notarse, resulta claro que la década de 1820 es un parte aguas en la actividad agrícola riograndense. Por un lado, se nota muy bien el período de auge de la agricultura, con altas frecuencias de presencia de herramientas en los inventarios. Resulta interesante también la menor frecuencia de arados en relación a las hoces específicas de cortar trigo (declaradas en los inventarios como «foices de ceifar trigo»). Esta diferencia estaría dando cuenta de distintas tecnologías en los cultivos: mientras el arado era utilizado probablemente en superficies más planas y libres de forestación, en otros espacios su utilización no era necesaria o indispensable. Nos referimos específicamente a los distritos al norte del río Jacuí (Santo Amaro y segundo distrito de Triunfo), donde abundaban las tierras onduladas o con mata nativa. Allí se utilizaba un instrumento muy precario, el palo cavador, que aunque no era declarado en los inventarios, su uso debió de haber estado ampliamente difundido. Era una herramienta muy versátil, que se adaptaba no sólo a terrenos irregulares, sino también a sementeras en las que se aplicaba el método de quema y roza de florestas.

Sin embargo, desde 1822 el panorama cambiaría: a partir de entonces la producción de trigo (y tal vez la agricultura en general) prácticamente desaparecería. Se trata de un fenómeno ampliamente conocido, derivado de problemas de enfermedad de los cultivos, apertura comercial y encarecimiento de la mano de obra y de la tierra, consecuencia del auge de los saladeros. Este nuevo con- 
texto generó costos de oportunidad que no podían ser afrontados por las prácticas agrícolas de entonces, lo que explica la gran caída de las herramientas agrícolas en los inventarios del período. La economía de la región desde ese momento se orientaría, como dijimos, hacia la producción de ganado y tasajo. Triunfo y Santo Amaro reflejan muy bien, en este sentido, el peso que tuvieron las coyunturas económicas y políticas sobre el territorio riograndense.

\section{CONCLUSIONES}

El renovado análisis de la historia agraria de las tierras meridionales del Brasil colonial y pos independiente ha permitido saltar el corsé impuesto por las historiografías nacionales y pensar el caso en base a sus particularidades regionales. Es decir, indagar sobre el paisaje agrario riograndense no sólo en base a su vinculación con las estructuras políticas y mercantiles luso-brasileñas, sino también a partir de una perspectiva rioplatense.

En este contexto, si bien los avances han sido notorios, algunos espacios no han sido aún detalladamente estudiados. Por ello en este artículo pusimos el foco en dos particulares distritos, las freguesias de Triunfo y Santo Amaro. Con una dotación de factores que muy pronto impulsó el crecimiento de los stocks ganaderos, las actividades agrícolas y la instalación de saladeros, Triunfo y Santo Amaro tuvieron importantes mudanzas en los patrones de producción. En un primer momento, con un abundante y barato recurso tierra, con accesibles recursos forrajeros y mano de obra abundante, se consolidó un nicho de actividad pecuaria, combinado con actividades agrícolas. En términos generales, se replicó allí lo que Helen Osório había probado para toda la Capitanía de Río Grande. Aunque también primaron en este espacio importantes diferencias regionales: mientras que en el primer distrito, ubicado al sur del río Jacuí predominaron los grandes criadores, en el segundo, al otro lado del río, la proporción de criadores y agricultores era más equilibrada, al igual que en el distrito de Santo Amaro, vecino de este último. Estos resultados, tomados de la Relação de Moradores de 1784 presentaron una primera imagen de la economía pecuaria de Triunfo.

Por lo demás, extendimos el análisis a lo largo del tiempo mediante el procesamiento de expedientes sucesorios. Se realizó una muestra de 114 inventarios, que fueron agrupados por décadas. Los resultados expuestos mostraron un fuerte impacto de los ciclos económicos en la pautas de inversión y en las estrategias productivas. El primer punto analizado fue el comportamiento de la ganadería a lo largo de las seis décadas que abarca este estudio. Se vio así que durante la década de 1790 predominó en Triunfo y Santo Amaro un panorama similar al que había mostrado la evidencia resultante del censo de 1784; esto es, una importan- 
te actividad pecuaria, con predominio de bovinos, equinos y mulares en menor medida, y presencia importante de bueyes, que indicarían también la práctica de actividades agrícolas. Esta imagen cambiaría en las dos primeras décadas del siglo XIX, con un fuerte deterioro de las inversiones en ganado, en detrimento de los activos en tierras y esclavos. A pesar de la coincidencia con otros espacios de la región, en el caso de Triunfo y Santo Amaro fue más pronunciado. Este proceso pudo haber estado impulsado por dos motivos: por un lado, por un acelerado ciclo de faena de reses bovinas destinadas a los mercados domésticos y atlánticos (en auge durante la segunda década del siglo XIX) y la coyuntura bélica demandante de carne; y por otro, debido a un cambio de estrategia productiva. O sea, impulsados por mejores costos de oportunidad, los productores volcaron los capitales hacia la agricultura triguera. Señales de este fenómeno no faltan: a la baja en las inversiones en ganado, se sumaron el crecimiento sostenido de las exportaciones de trigo, el alza en el valor de los esclavos (motivado seguramente por una mayor utilización del componente de mano de obra) y un aumento en las frecuencias de herramientas en los inventarios. Si bien son meras conjeturas, los casos de Triunfo / Santo Amaro ayudan, en efecto, a arriesgar esta hipótesis.

Es por ello que la década de 1820 abriría a una nueva coyuntura productiva, impulsada por los altos precios de los commodities pecuarios y el vuelco definitivo hacia la economía de saladeros. Varios motivos fueron responsables de esta emergencia, aunque se destacan con mayor énfasis la particular dotación de factores de las freguesias y la crisis ganadera derivada de las guerras de la independencia en las colonias españolas, que habían afectado fuertemente la oferta proveniente de los saladeros rioplatenses. En ese contexto, los saladeros riograndenses se posicionaron como un polo productor con grandes ventajas relativas. Este proceso tuvo efectos variados: revitalizó los stocks vacunos, incrementó el valor monetario de los esclavos y cambió el eje en un espacio económico antes caracterizado por actividades mixtas.

La Revolución Farroupilha iniciada en 1835 sería el inicio del fin del ciclo saladerista en Triunfo. Su impacto en la disminución de los planteles ganaderos de la región, y sobre todo en la logística y el funcionamiento de los saladeros, generó un primer problema, que se haría más evidente en la década de 1840, cuando comenzaba a tomar forma la expansión hacia fronteras más alejadas y especializadas en ganadería extensiva. La consolidación del núcleo saladeril de Pelotas, en torno al puerto de Rio Grande, ofreció mejores ventajas geográficas que terminaron por afectar a los saladeros de Triunfo. Fue así que para el final del período, las freguesias de Triunfo y Santo Amaro se habían convertido en un escenario diferente, no ya dominado por los saladeros, sino por un nuevo esquema ganadero en el que cobrarían nuevamente importancia los pequeños y medianos criadores. 


\section{ApÉNDICE ESTÁDÍSTICO}

\section{ApÉNDICE 1. EVOLUCIÓN COMPARATIVA DE LAS INVERSIONES EN GANADO EN DIFERENTES DISTRITOS DE RIO GRANDE, 1790-1849}

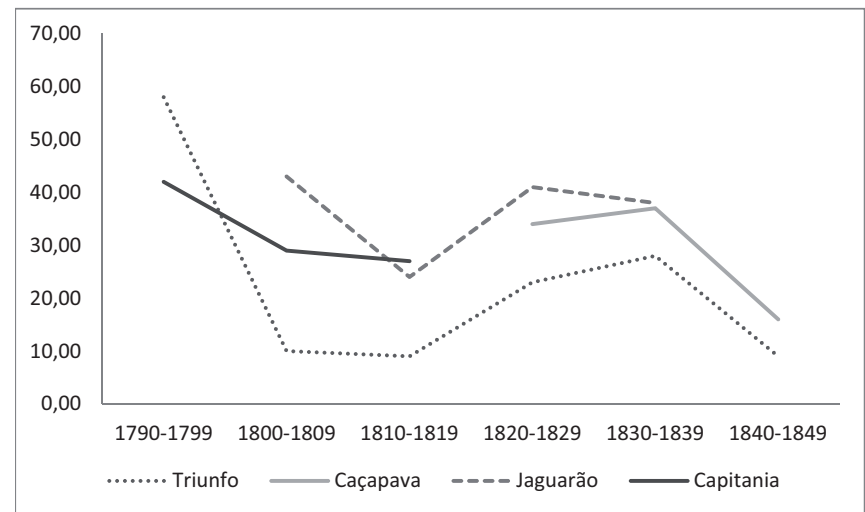

Fuente: elaboración propia en base a Osório, 1999: 101; Gularte, 2015: 67; Corrêa, 2013: 57. Vale destacar que los cálculos de Osório para la década de 1820 sólo comprenden el primer lustro de la misma y los de Gularte para Jaguarão correspondientes a la década de 1830 sólo incluyen hasta 1834.

\section{ApÉNDICE 2. EVOLUCIÓN COMPARATIVA DE LAS INVERSIONES EN ESCLAVOS EN DIFERENTES DISTRITOS DE RIO GRANDE, 1790-1849}

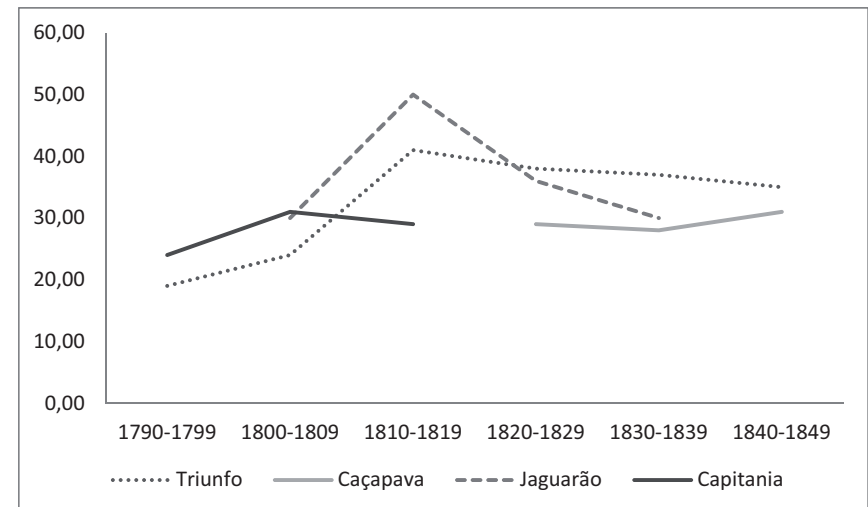

Fuente: idem apéndice 1. 
Apéndice 3. Evolución de las exportaciones agropecuarias de Rio Grande, 1790-1849, EN CANTIDADES FÍSICAS. INDICE 100=PROMEDIO

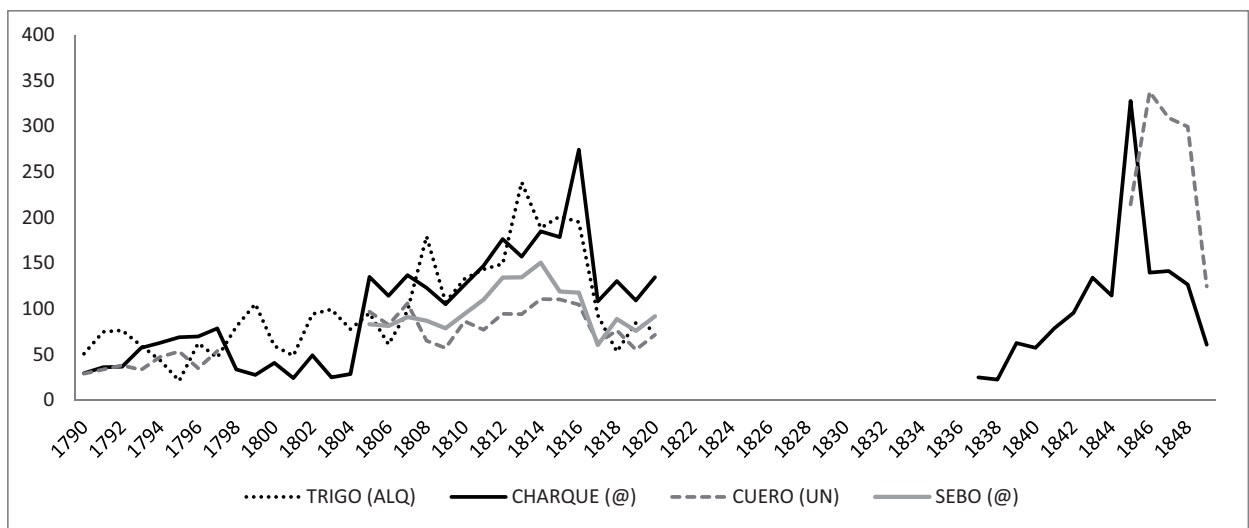

Fuente: elaboración propia con base en Medeiros dos Santos (1983: 141-142).

Apéndice 4. Precios del ganado bovino, equino y mular en Triunfo / Santo Amaro, 1790-1849. Promedios POR DÉCADAs, EXPRESAdos EN MilReis

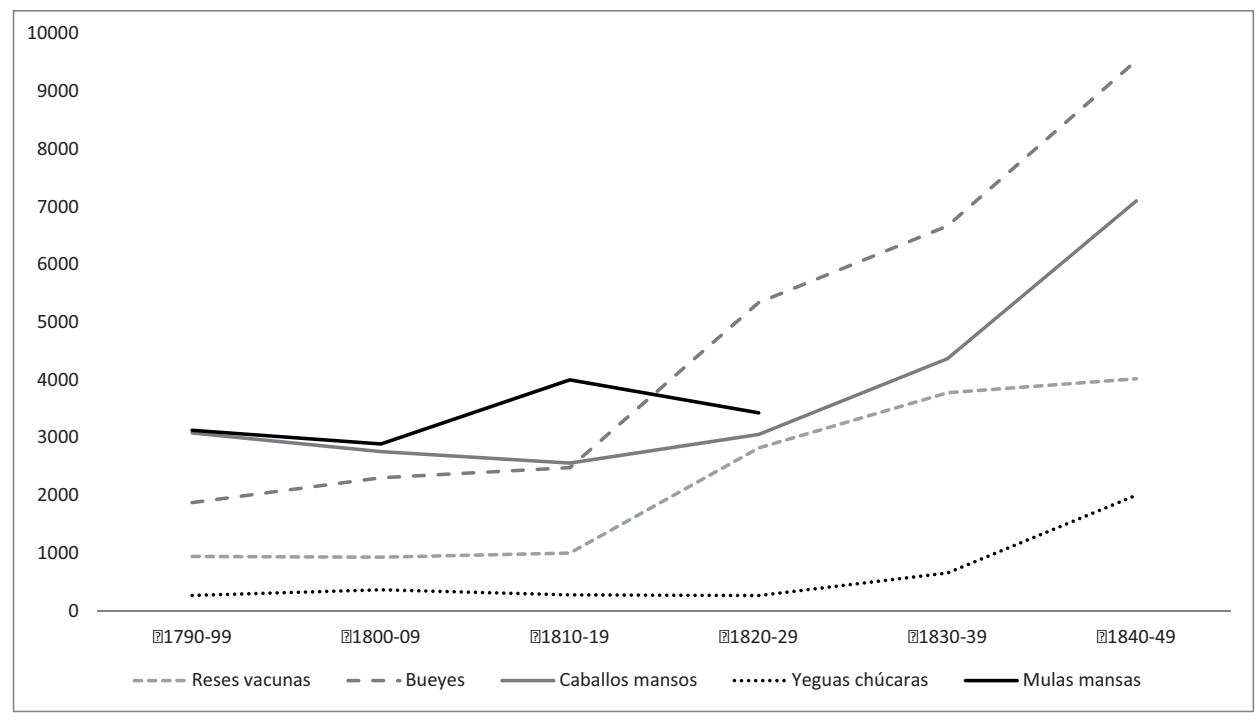

Fuente: idem gráfico 2. 
¿UN ESPACIO RIOPLATENSE AMPLIADO? ANÁLISIS DE UNA ECONOMÍA AGRARIA EN EL SUR DE BRASIL... 435

Apéndice 5. Valor de los esclavos Según franja etaria en Triunfo / Santo Amaro, 1790-1850. Promedios POR DÉCADAS, EXPRESADOS EN MILREIS

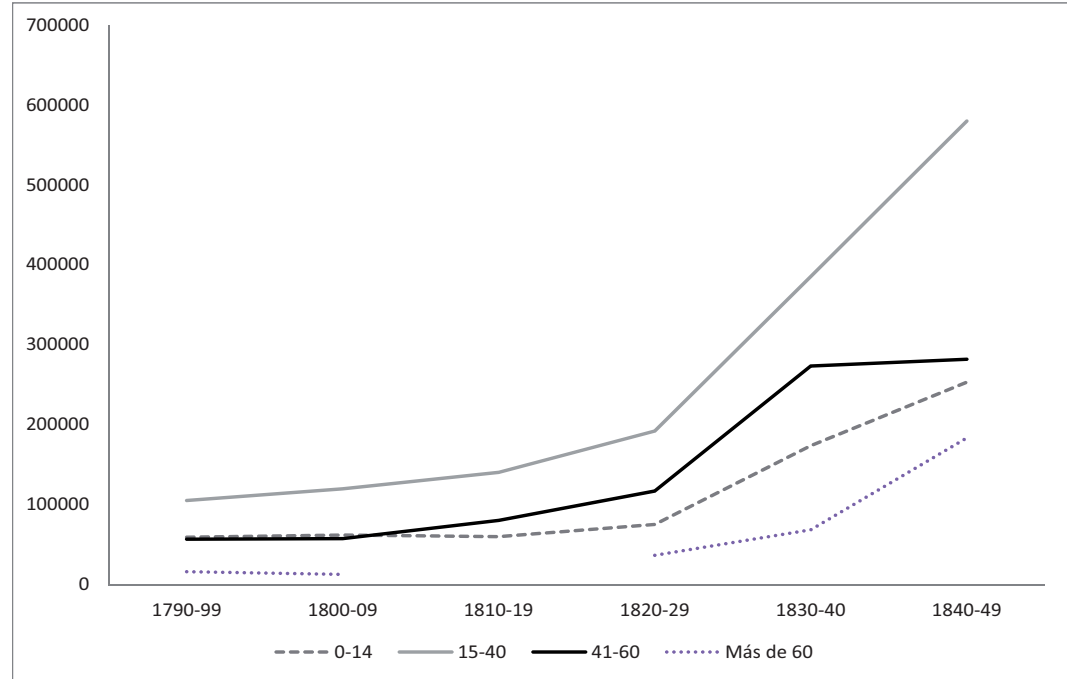

Fuente: idem gráfico 2.

ApÉNDICE 6. EvoluCión DEL REBAÑo EQUINO EN CANTIDAD Y CAPITALIZACIÓN, $1790-1850$

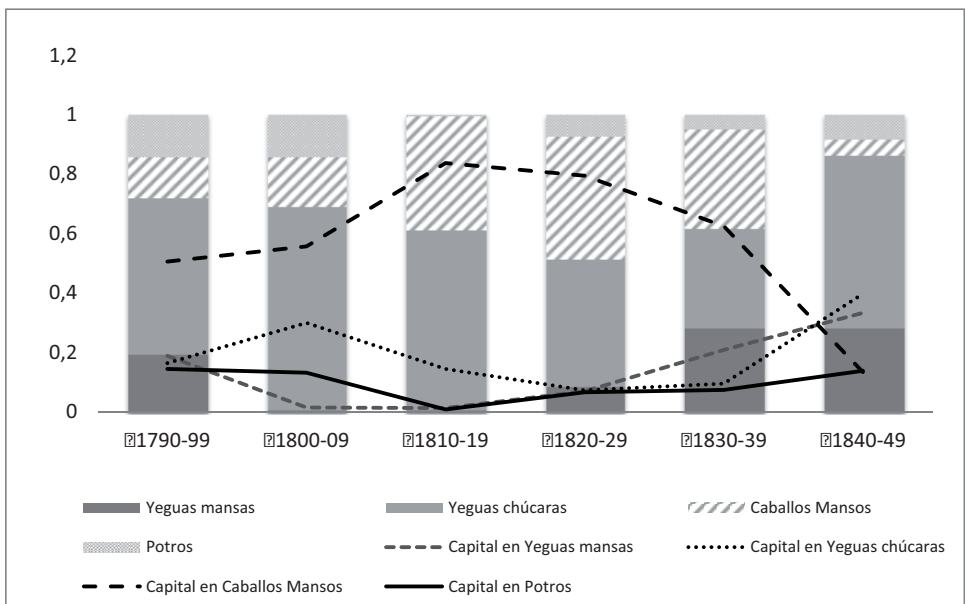

Fuente: idem gráfico 2. 


\section{BIBLIOGRAFÍA}

Aladren, Gabriel, Sem respeitar fé nem tratados: escravidão e guerra na formação histórica da fronteira do sul do Brasil (Rio Grande de São Pedro, 1777-1835), tesis doctoral, Niterói, Brasil, Universidade Federal Fluminense, 2012.

Almeida, Carla, Alterações nas unidades de produções mineiras: Mariana, 17501850, tesis doctoral, Niterói, Brasil, Universidade Federal Fluminense, 1994.

Alvim, Alexandra Lis, Das Ilhas ao Continente: estratégias de inserção social dos imigrantes açorianos na povoação de Santo Amaro, $R S$, através dos registros batismais (1757-1774), trabalho de Conclusão de Curso, Porto Alegre, Brasil, Universidad Federal do Rio Grande do Sul, 2012.

Amaral, Samuel, The rise of capitalism on the Pampas: the Estancias of Buenos Aires, 1785-1870, Cambridge / Nueva York / Melbourne, Cambridge University Press, 1998.

Barickman, Bert, Um contraponto baiano: açúcar, fumo, mandioca e escravidão no Recôncavo, 1780-1860, Río de Janeiro, Civilização Brasileira, 2003.

Barriera, Darío y Fradkin, Raúl (coords.), Gobierno, justicias y milicias. La frontera entre Buenos Aires y Santa Fe, 1720-1830, La Plata, FaHCE, 2014.

Barroso, Vera Lúcia Maciel (org.), Açorianos no Brasil, Porto Alegre, EST, 2002.

Bertulini, Luiza, A vila do Rio Grande de São Pedro, tesis de maestria, Florianoplis, Brasil, Universidade Federal de Santa Catarina, 1985.

Berute, Grabriel dos Santos, Atividades Mercantis do Rio Grande de São Pedro: Negócios, Mercadorias e Agentes Mercantis (1808-1850), tesis doctoral, Porto Alegre, Brasil, Universidade Federal do Rio Grande do Sul, 2011.

Borges Fortes, J., Os casais açorianos: presença lusa na formação do Rio Grande do Sul, Porto Alegre, Martins Livreiro, 1999 [1932].

Canedo, Mariana, "Los pueblos de españoles en la monarquía hispánica. La ampliación de jurisdicciones hacia el autogobierno (Buenos Aires, siglo XVIII y primeros años del XIX)", Prohistoria, 19/25 (Rosario, 2016): 2-27.

Carvalho, Vera Regina, "Da ilha dos Açores à freguesia de Taquari: uma trajetória dos imigrantes açorianos no Continente do Rio Grande", Estudo e Debate, 9/1 (Lajeado, Brasil, 2002): 39-57.

Castro, Hebe Maria Mattos, Ao Sul da História: lavradores pobres na crise do trabalho escravo, São Paulo, Brasiliense, 1987.

Christillino, Cristiano, Estranhos em seu próprio chão. O processo de apropriação e espropriação de terras na Província de São Pedro do Rio Grande do Sul (O Vale de Taquari no periodo de 1840-1889), tesis de maestría, São Leopoldo, Brasil, Universidade do Vale do Rio dos Sinos, 2004. 
Comissoli, Adriano, À serviço da Sua Majestade: adiministração, elite e poderes no extremo meridional brasileiro, 1808-1831), Río de Janeiro, Brasil, Universidade Federal do Rio de Janeiro, 2011.

Corrêa, André do Nascimento, Ao sul do Brasil oitocentista. Escravidão e estrutura agrária em Caçapava, 1821-1850, tesis de maestría, Santa María, Brasil, Universidade Federal de Santa Maria, 2013.

Djenderedjian, Julio, Economía y sociedad en la Arcadia criolla. Formación y desarrollo de una sociedad de frontera en Entre Ríos, 1750-1820, tesis de doctorado, Buenos Aires, Argentina, Universidad de Buenos Aires, 2003.

Djenderedjian, Julio y Martiren, Juan Luis, "Consumption Baskets and Cost of Living in Southern Late Colonial Brazil: Rio Grande, 1772-1823”, Revista de Historia Económica - Journal of Iberian and Latin American Economic History, 38/Special Issue 2 (Madrid, 2020): 279-309.

Eckhardt, Sandra Roth, "Pequenos produtores de São Jose de Taquary: um perfil dos moradores em 1784", Amanda Basilio Santos, Jonas Vargas y Elisabete Leal (orgs.), Fronteiras e identidades. Reunião de artigos do III EIFI, Pelotas, Edição do autor, 2017: 1-12.

Estado do Rio Grande do Sul, De província de São Pedro a Estado do Rio Grande do Sul, Porto Alegre, Fundação de Economia e Estatística, 1981.

Fabrício, José de Araujo, “A Freguesia de Nosso S. Bom Jesús do Triunfo. Seus primeiros povoadores, na segunda metade do século XVIII", Revista do Instituto Histórico e Gegráfico do Rio Grande do Sul, 105-108 (Porto Alegre, 1947): 229342.

Faria, Sheila de C., A Colônia em Movimento: fortuna e família no cotidiano colonial, Río de Janeiro, Nova Fronteira, 1998.

Farinatti, Luís Augusto Ebling, Confins meridionais: famílias de elite e sociedade agrária na Fronteira Sul do Brasil (1825-1865), tesis doctoral, Río de Janeiro, Universidad Federal de Rio de Janeiro, 2007.

Farinatti, Luís Augusto Ebling, "La Historia Agraria en el sur de Brasil: un panorama sobre los últimos avances historiográficos", Boletín del Instituto de Historia Argentina y Americana Dr. Emilio Ravignani, 48 (Buenos Aires: 2017): 174-206.

Florentino, Manolo, Em costas negras: uma história do tráfico atlântico de escravos entre a África e o Rio de Janeiro (século XVIII e XIX), São Paulo, Cia das Letras, 1997.

Fradkin, Raúl, "Caminos abiertos en la Pampa. Dos décadas de renovación de la historia rural rioplatense desde mediados del siglo XVIII a mediados del XIX", Jorge Gelman (comp.), La historia económica en la encrucijada. Balances y perspectivas, Buenos Aires, Prometeo, 2006: 189-207. 
Fragoso, João L., Homens de Grossa Aventura: acumulação e hierarquia na praça mercantil do Rio de Janeiro (1790- 1830), Río de Janeiro, Editora Arquivo Nacional, 1992.

Garavaglia, Juan C., "Un siglo de estancias en Buenos Aires (1751-1853)", Hispanic American Historical Review, 79/4 (Durham, 1999): 703-734.

Gelman, Jorge, Campesinos y estancieros: una región del Río de la Plata a fines de la época colonial, Buenos Aires, Libros del Riel, 1998.

Gelman, Jorge, Rosas bajo fuego. Los franceses, Lavalle y la rebelión de los Estancieros, Buenos Aires, Sudamericana, 2009.

Gelman, Jorge y Garavaglia, Juan C., "Mucha tierra y poca gente: Un nuevo balance historiográfico de la historia rural platense", Historia agraria: Revista de agricultura e historia rural, 15 (Murcia: 1995): 29-50.

Gil, Tiago, Coisas do caminho Tropeiros e seus negócios do Viamão à Sorocaba (1780-1810), tesis doctoral, Río de Janeiro, Universidad Federal de Río de Janeiro, 2009.

Gomes, Luciano da Costa, Camponeses e pequenos escravistas: estrutura econômica, reprodução social e vínculos extradomiciliares de produtores rurais em Porto Alegre e Viamão, décadas finais do século XVIII, tesis doctoral, Porto Alegre, Brasil, Universidade Federal do Rio Grande do Sul, 2018.

Guazzelli, Cesar Augusto Barcellos, Horizonte da Provincia. A República Riograndense e os caudilhos do Rio da Prata (1835-1845), tesis doctoral, Río de Janeiro, Universidad Federal de Rio de Janeiro, 1998.

Gularte, Gustavo da Silva, Fronteira do Jaguarão: unidades produtivas e trabalho escravo na formação de um espaço fronteiriço, 1801-1835, tesis de maestría, Porto Alegre, Brasil, Universidad Federal do Rio Grande do Sul, 2015.

Hameister, Marta, O continente do Rio Grande de São Pedro: os homens, suas redes de relações e suas mercadorias semoventes, tesis de maestría, Río de Janeiro, Brasil, Universidade Federal do Rio de Janeiro, 2002.

Hameister, Marta, "Notas sobre a construção de uma identidade açoriana na colonização do sul do Brasil ao século XVIII", Anos 90, 12/21-22 (Porto Alegre, 2005): 53-101.

Henderson, James, History of the Brazil, London, Longman \& Co., 1821.

Kühn, Fabio, Gente da Fronteira. Familia, Sociedade e Poder no sul da América Portuguesa, século XVIII, tesis doctoral, Niterói, Brasil, Universidade Federal Fluminense, 2006.

Leitman, Spencer, Raízes socioeconômicas da Guerra dos Farrapos: um capítulo da História do Brasil no século XIX, Río de Janeiro, Graal, 1979.

Marques, Alvarino da F., Episódios do ciclo do charque, Porto Alegre, Edigal, 1987. 
Mattos, Hebe, Das cores do silêncio: os significados da liberdade no sudeste escravista. Brasil século XIX, Río de Janeiro, Nova Fronteira, 1998.

Mawe, John, Travels in the interior of Brazil, London, Longman \& Co., 1812.

Menz, Maximiliano, Entre Dois Impérios: Formação do Rio Grande na crise do Antigo Sistema Colonial, 1777-1822, tesis doctoral, São Paulo, Brasil, Universidade de São Paulo, 2006.

Osório, Helen, Apropriação da Terra no Rio Grande de São Pedro e a Formação do Espaço Platino, tesis de maestría, Porto Alegre, Brasil, Universidade Federal do Rio Grande do Sul, 1990.

Osório, Helen, Estancieiros, lavradores e comerciantes na constituição da Estremadura portuguesa na América. Rio Grande de São Pedro (1737-1822), tesis doctoral, Río de Janeiro, Brasil, Universidad Federal Fluminense, 1999.

Osório, Helen, "Comerciantes do Rio Grande de São Pedro: formação, recrutamento e negócios de um grupo mercantil da Amérca Portuguesa", Revista Brasileira de Historia, 20/39 (São Paulo, 2000): 99-134.

Osório, Helen, "Estancieiros que plantam, lavradores que criam e comerciantes que charqueiam: Rio Grande de São Pedro, 1760-1825”, Luis Grijó, Fabio Kühn, Cézar Barcellos Gazzelli y Edurardo Neumann (orgs.), Capítulos da História do Rio Grande do Sul, Porto Alegre, Editora da UFRGS, 2004: 75-90.

Osório, Helen, "Guerra y comercio en la frontera hispano-portuguesa meridional. Capitanía de Río Grande, 1790-1822”, Raúl Fradkin, (org.), Conflictos, negociaciones y comercio durante las guerras de independencia latinoamericanas, New Jersety, Gorgias Press, 2010.

Osório, Helen, “A organização territorial em um espaço de fronteira com o império espanhol e seu vocabulário. Notas de pesquisa", Claves. Revista de Historia, 1 (Montevideo, 2015): 67-90.

Salis Gulart, Jorge, A formação do Rio Grande, Porto Alegre, Martins Livreiro, 1985 [1927].

Salvatore, Ricardo, Paisanos itinerantes. Orden estatal y experiencias subalternas en Buenos Aires durante la era de Rosas, Buenos Aires, Prometeo, 2018.

Santos, Corcino Medeiros dos, Economia e Sociedade do Rio Grande do Sul, Século XVIII, San Pablo, Companhia Editora Nacional, 1983.

Schmit, Roberto y Rosal, Miguel A., "Política comercial, flujos mercantiles y negocios: Buenos Aires y Montevideo frente al comercio exterior rioplantense en el siglo XIX”, Revista de Indias, 59/215 (Madrid, 1999): 91-122.

Spalding, Walter, Gênese do Brasil-Sul, Porto Alegre, Globo, 1953. 
Vargas, Jonas M., Os Barões do charque e suas fortunas. Um estudo sobre as elites regionais brasileiras a partir de uma análise dos charqueadores de Pelotas (Rio Grande do Sul, século XIX), San Leopoldo, Oikos, 2016.

Volkweis, Roberta, A presença portuguesa no processo de formação das cidades do Brasil Meridional. A questão da origem açoriana de Triundo, $R S$, tesis de Maestría, Porto Alegre, Brasil, Universidade Federal do Rio Grande do Sul, 2011.

Zarth, Paulo, Do Arcaico ao Moderno. O Rio Grande do Sul agrario durante o século XIX, Ijui, Editora Unijui, 2002.

Fecha de recepción: 5 de febrero de 2019 .

Fecha de aceptación: 9 de agosto de 2019.

\section{An extended Rio de la Plata region? Analysis of an agrarian economy in the south of Brazil (Triunfo and Santo Amaro, 1784-1849)}

The article analyses the evolution of a frontier agrarian economy in southern Brazil between 1784 and 1849. To this end, we focus on the districts of Triunfo and Santo Amaro, located in what is currently the state of Rio Grande do Sul. The two districts are relevant in both economic and geographic terms, since they were not only of strategic importance in the Portuguese advance towards Río de la Plata, but also experienced considerable growth in agriculture in the late colonial period and in the beef jerky industry as of the 1820s. Using census and probate records, we have sought to measure change and continuity in livestock, agriculture and production strategies. The results are similar to those already known for Rio Grande do Sul during the same period, and coincide to some extent with those found for the Río de la Plata region.

Key words: Agriculture; Livestock; Rio Grande Captaincy; Río de la Plata. 